Review

\title{
Roles of sex and gonadal steroids in mammalian pheromonal communication
}

\author{
Michael J. Baum ${ }^{\mathrm{a}, *}$, Julie Bakker ${ }^{\mathrm{b}, \mathrm{c}}$ \\ ${ }^{a}$ Dept. of Biology, Boston University, 5 Cummington St., Boston, MA 02215, USA \\ ${ }^{\mathrm{b}}$ GIGA Neuroscience, University of Liege, Liege, Belgium \\ ${ }^{\mathrm{c}}$ Netherlands Institute for Neuroscience, Amsterdam, The Netherlands
}

\section{A R T I C L E I N F O}

\section{Article history:}

Available online 18 July 2013

\section{Keywords:}

Testosterone

Estradiol

Sexual behavior

Medial amygdala

Olfactory bulb

\begin{abstract}
A B S T R A C T
A brain circuit (the accessory olfactory system) that originates in the vomeronasal organ (VNO) and includes the accessory olfactory bulb (AOB) plus additional forebrain regions mediates many of the effects of pheromones, typically comprised of a variety of non-volatile and volatile compounds, on aspects of social behavior. A second, parallel circuit (the main olfactory system) that originates in the main olfactory epithelium (MOE) and includes the main olfactory bulb (MOB) has also been shown to detect volatile pheromones from conspecifics. Studies are reviewed that point to specific roles of several different steroids and their water-soluble metabolites as putative pheromones. Other studies are reviewed that establish an adult, 'activational' role of circulating sex hormones along with sex differences in the detection and/or processing of non-steroidal pheromones by these two olfactory circuits. Persisting questions about the role of sex steroids in pheromonal processing are posed for future investigation.
\end{abstract}

(c) 2013 Elsevier Inc. All rights reserved.

\section{Introduction}

Pheromones are compounds of varying chemical structure that are excreted in bodily fluids (e.g., urine, feces, tears, or sweat) from individuals of a species which are detected by the olfactory nervous system of a conspecific so as to influence aspects of its neuroendocrine and/or behavioral function (Karlson and Luscher, 1959; Meredith, 2001). Some authors (McClintock, 2002) have subdivided mammalian pheromones into 4 groups according to functions that include 'release' of some stereotyped behavior, 'priming' of some neuroendocrine response, 'signaling' a social status, or 'modulating' some ongoing behavior or psychological process. We will make no explicit distinction among any of these types of function in our use of the term 'pheromone'. We also note that some authors (Petrulis, 2013) prefer to avoid use of the term 'pheromone' to refer to the general class of chemical signaling molecules that influence conspecifics' behavior/neuroendocrine functions because relatively few compounds produced in mammals (as opposed to insects) meet all of the rigorous criteria originally used to define a 'pheromone'. Chief among these is the notion that an authentic pheromone is a single compound that elicits a response that is 'hard wired' and unaffected by prior experience. We prefer to retain the use of the word 'pheromone' as a convenient term that refers to any mammalian chemosignal that

\footnotetext{
* Corresponding author.

E-mail address: baum@bu.edu (M.J. Baum).
}

influences a conspecifics' behavior. Note that we also use the term, 'pheromone' to refer to yet-to-be specified combinations of different 'signature mixtures' of compounds that influence conspecifics' behavior (Wyatt, 2010). We think it is pointless to argue over the strict 'pheromonal' status of each compound that has been/will be identified as exerting an influence on mammalian neuroendocrine or behavioral function.

In rodents and other terrestrial vertebrates the vomeronasal organ (VNO) was previously considered to be the primary, if not the sole, 'pheromone detection system' (Chamero et al., 2012; Tirindelli et al., 2009). VNO receptor neurons located in the roof of the mouth extend axons to glomeruli located in the accessory olfactory bulb (AOB) where they synapse onto the dendrites of AOB mitral cells which extend axons to the medial amygdala (MeA; part of the 'vomeronasal amygdala') (Kevetter and Winans, 1981a). Neurons in the MeA project, in turn, to hypothalamic targets including the bed nucleus of the stria terminalis (BNST), the medial preoptic area ( $\mathrm{MPOA}$ ), and the ventromedial hypothalamus (VMH). Individual VNO sensory neurons express a single receptor protein (encoded by one of 2 separate gene families of $\sim 250$ genes) that presumably detect specific pheromones, although specific pheromonal ligands for specific receptor proteins have yet to be identified (Dulac and Axel, 1995). Many investigators believe that VNO sensory neurons respond mainly to non-volatile pheromones (which may be peptides or even larger proteins). In some instances, large proteins (e.g., lipocalins) may bind and deliver smaller pheromonal molecules (e.g., 2-secbutyl-4,5-dihydrothiazole) to the 
VNO neuroepithelium (Novotny, 2003). The relatively heavy, nonvolatile compounds (as well as sulfated steroids and perhaps even unconjugated sex hormones; see below) are dissolved in mucus and gain access to the VNO neuroepithelium via a vascular pumping mechanism controlled by the sympathetic innervation of blood vessels in the VNO (Meredith and O'Connell, 1979). The main olfactory epithelium (MOE) is clearly the detection system for all general (non-pheromonal) odorants present in the environment (Xu et al., 2000). Olfactory receptor neurons in the MOE express a single receptor gene from a large family of $\sim 900$ different genes (Buck and Axel, 1991). MOE olfactory neurons expressing the same receptor gene extend axons to 1-2 specific glomeruli located on the surface of the main olfactory bulb (MOB) where they synapse with dendrites of mitral cells that project extensively to diffuse target sites in the olfactory tubercle and in the anterior as well as the posterior piriform cortex (Sosulski et al., 2011). An early study (Kevetter and Winans, 1981b) demonstrated that a subset of MOB mitral cells also project to cortical amygdaloid nuclei ('olfactory amygdala'). However, more recent studies (Kang et al., 2009; Pro-Sistiaga et al., 2007; Thompson et al., 2012) showed that there is a subpopulation of MOB mitral cells that also project directly to the MeA ('vomeronasal amygdala'). There is considerable evidence from numerous studies conducted over the past 20 years that several volatile chemicals (including the androgenic steroid, androstenone) function as pheromones that influence aspects of behavior and neuroendocrine function after their detection by a specialized population of receptor neurons in the MOE. A summary of the neuroanatomy of the accessory and main olfactory systems in the mouse, including projection targets to the forebrain, is provided in Fig. 1. Note that there exist at least two, additional, specialized components of the mammalian olfactory nervous system (i.e., the septal organ of Masera and the Grueneberg ganglion) whose possible role in pheromonal processing has yet to be determined (Brennan and Zufall, 2006),

In this review we will first consider evidence pointing to specific steroid molecules that function as pheromones in their own right. Next we will review literature showing that there are both sex differences in pheromone detection and processing as well as adult, activational effects of circulating sex hormones on the neuronal processing of pheromones. In many instances, perinatal sex

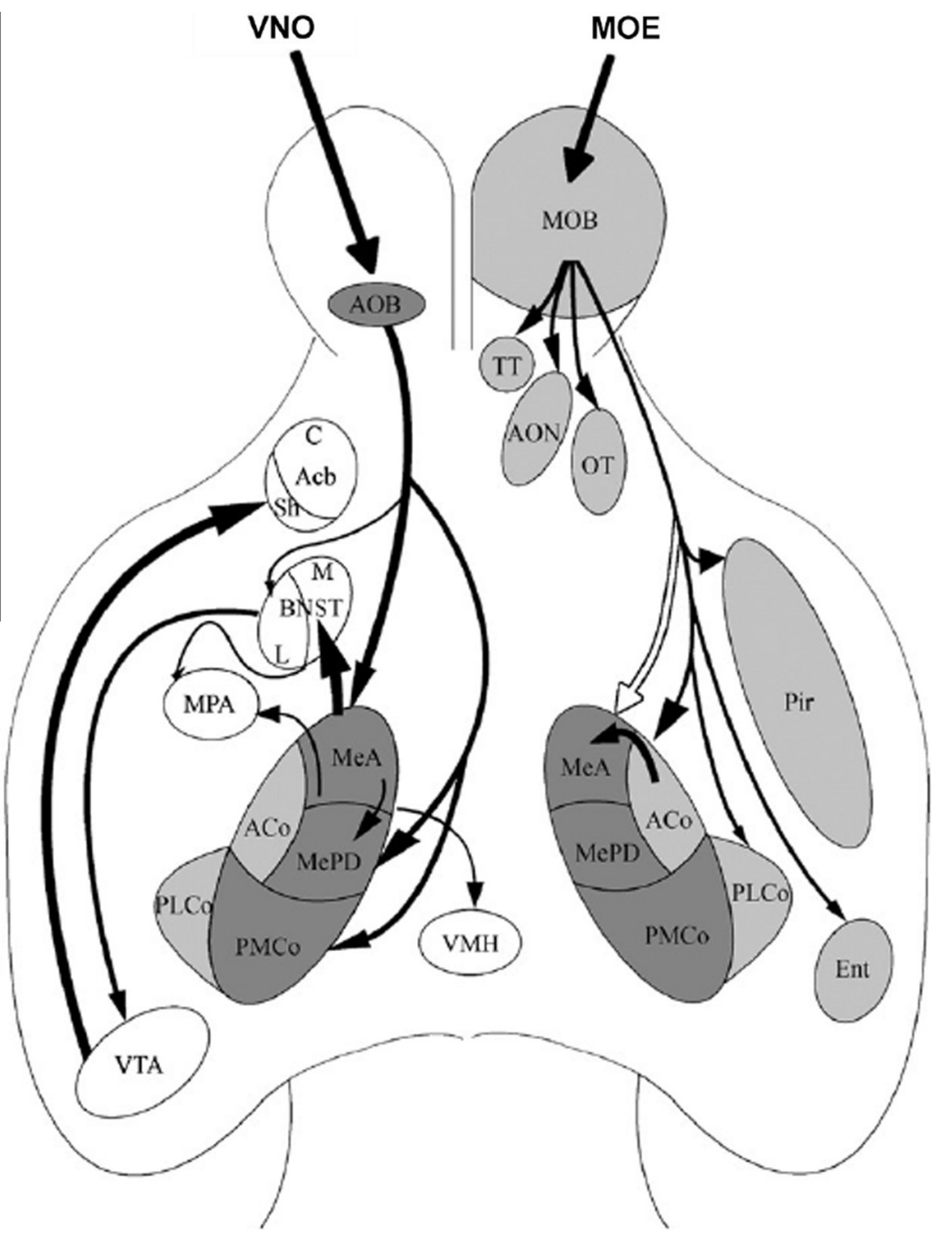

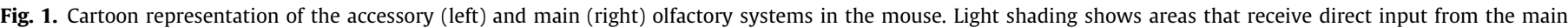

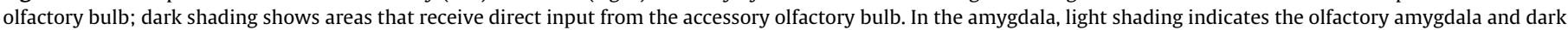

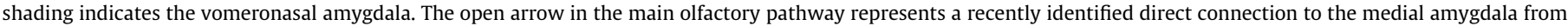

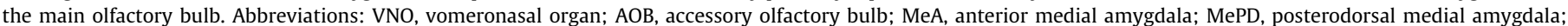

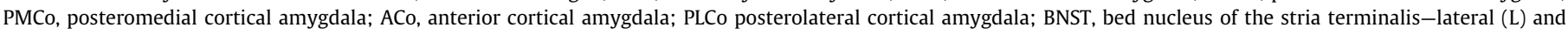

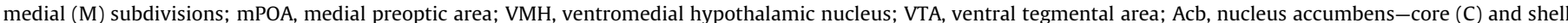

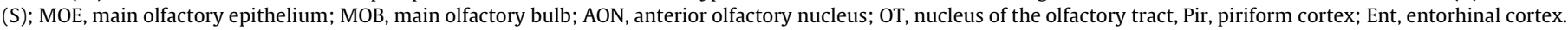
Reproduced with permission (Baum, 2009). 
differences in the neural actions of circulating testosterone (or of estradiol formed directly in the brain from circulating testosterone) in the male will be linked to adult sex differences in pheromonal processing. We then will review literature showing that subjects' sex as well as adult exposure to circulating sex hormones cause striking behavioral differences in their responses to pheromones. Throughout, we will cite examples of our own published work to illustrate each of the above topics. Finally, we will specify several topics in the general domain of sex, sex steroids, and pheromones that warrant future investigation.

\section{Sex steroids and their metabolites/analogues as putative pheromones}

\subsection{Androgenic steroids}

The early work of Signoret $(1967,1970)$ established that the volatile androgenic steroid, androstenone, is excreted in the saliva of male pigs (boars) in breeding condition and serves both to attract the estrous female and to facilitate her receptive posturing in response to a male's mounting attempt. More recently, it was shown that females are better able than males to detect low concentrations of androstenone (Dorries et al., 1995) (more on this later) and that the main, as opposed to the accessory, olfactory system is primarily responsible for the ability of estrous sows to detect and respond to androstenone (Dorries et al., 1997). Another, structurally related steroid, androstadienone (AND), is produced in underarm sweat of male humans. Several studies raise the possibility that AND, which is synthesized from pregnenolone (it is not a metabolite of testosterone, as is stated by many authors), signals males' reproductive status to women, and perhaps to other men as well. Polymorphisms in the olfactory receptor protein, OR7D4, are associated with variations among individual humans in their ability to detect AND and in their ratings of its pleasantness (Keller et al., 2007). There was no distinction between men and women in the number of people who reported being unable to smell AND or androstenone in this study. However, in a previous report (Dorries et al., 1989) the ability to detect androstenone was more likely to diminish in boys than in girls after the age of puberty. Likewise, Hummel and co-workers (Chopra et al., 2008; Lundstrom et al., 2003) reported a decrease in sensitivity to AND in adolescent boys, compared to pre-pubertal boys, which was not observed in girls. Despite the lack of uniformity in the expression of MOE olfactory receptor proteins that are capable of detecting AND, there are several studies suggesting that AND may attract women to men or attract gay men to other gay men. In a systematic comparison of rated preferences for different underarm odors, heterosexual women preferred the smell of underarm odors from heterosexual as opposed to gay men while gay men preferred underarm odors of other gay men (Martins et al., 2005). The authors raised the possibility that differences in the preference for the putative male underarm pheromone, AND, may underlie this profile of preferences, although this was not tested directly. Much evidence (Frasnelli et al., 2011; Trotier et al., 2000) suggests that adult humans lack functional VNO sensory neurons that extend axons to an AOB. Thus, the putative pheromonal actions of AND must result from its detection by a population of sensory neurons in the MOE and further processing of inputs along a pathway that may include the medial amygdala (Turner et al., 1978) and the hypothalamus.

\subsubsection{Neural processing of AND}

Savic and co-workers used PET scanning to compare the profile of hypothalamic neuronal activation induced by application of a very high dose of AND to the upper lip of straight vs. gay men and women as well as transgendered persons. In an initial study (Savic et al., 2001) AND induced hypothalamic activation in heterosexual women, but not in men. Gay men were subsequently found to show hypothalamic activation in response to AND that resembled that seen in heterosexual women (Savic et al., 2005). Lesbian women failed to show hypothalamic PET responses to AND (Berglund et al., 2006), and in this respect resembled heterosexual men. In another study (Berglund et al., 2008) $46 \mathrm{XY}$ male to female transsexuals, who were all gynaphilic (heterosexual), showed a significant hypothalamic PET response to AND that resembled the response seen in heterosexual women. Finally, (Ciumas et al., 2009) significant AND-induced PET activation in the hypothalamus was seen in women with congenital adrenal hyperplasia and in whom fetal testosterone signaling was very likely higher than in the normal control women. This outcome calls into question the common assumption that fetal testosterone signaling in gestating boys is the main determinant of the reported sex difference in hypothalamic responses to AND. More research will be needed to resolve this issue. There is also a lingering question from these studies about the very high, non-physiological, concentration of AND that was applied to subjects' upper lips in all of the studies of Savic and her colleagues. Burke and coworkers (Burke et al.) (Fig. 2) used fMRI to image hypothalamic responses to several different concentrations of AND in heterosexual men vs. heterosexual women. These investigators replicated the sex difference (only women showed a hypothalamic response) reported by Savic et al. (2001) in subjects exposed to the highest concentration of AND, which was delivered as a vapor using an olfactometer instead of being applied in crystalline form to the upper lip. However, when a medium concentration of AND vapor was administered, male subjects actually showed a more robust hypothalamic fMRI
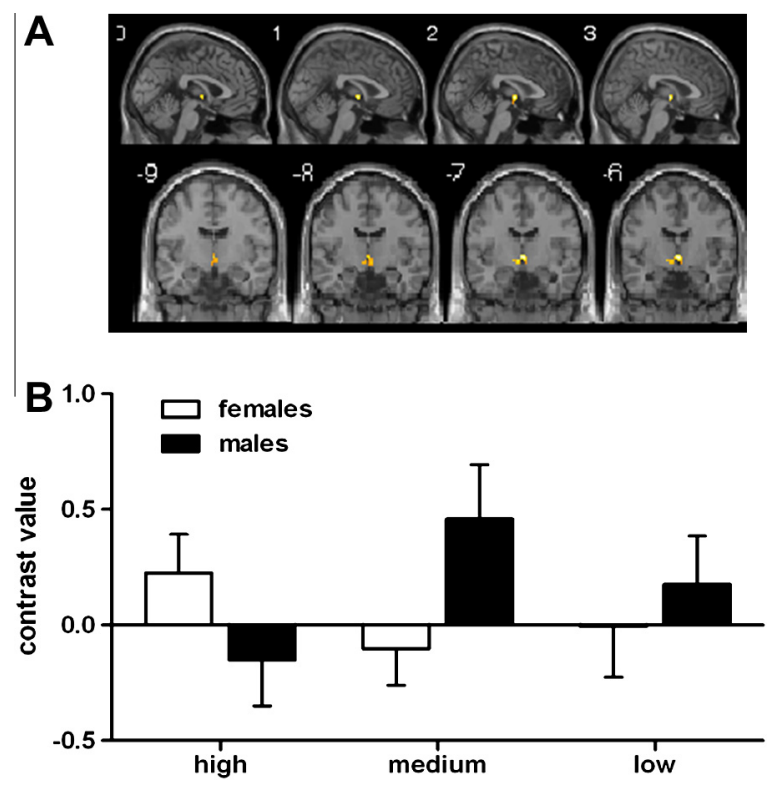

Fig. 2. Panel A. F contrast depiction of male vs. female group differences in hypothalamic activation from human subjects exposed to a 'high' concentration of androstadienone. The image coordinates shown $(x=2 ; y=-6 ; z=0)$ are expressed in Montreal Neurological Institute brain atlas space. Panel B. The activation of hypothalamic neuronal activity, reflected in fMRI contrast value, was significantly greater in heterosexual adult women (females) than in heterosexual adult men (males) who smelled a 'high' concentration of the putative human male pheromone, androstadienone. A reverse sex difference (men > women) in hypothalamic activation was seen when subjects were presented with a 'medium' concentration of androstadienone. No sex difference was seen when subjects smelled a 'low' concentration of this volatile androgenic steroid. Data are expressed as means; error bars reflect 95\% confidence interval. Reproduced with permission from Burke et al. (2012). 
response to the putative pheromone than heterosexual women. No sex difference was seen in the hypothalamic response to a low concentration of AND (Fig. 2). This set of results demonstrates the merit of studying a range of putative pheromone concentrations in comparing the detection capacity of men and women as well as the potential adult activational effects of sex hormones on pheromone detection. These new results also raise the question of whether behavioral effects of AND can be demonstrated in heterosexual men, in addition to homosexual men and heterosexual women?

\subsubsection{Behavioral effects of AND}

Several studies have assessed the ability of AND to affect neuroendocrine as well as psychological functions related to mate recognition among women. Thus, application of AND to the upper lip of heterosexual women significantly augmented salivary levels of cortisol (Wyart et al., 2007). Surprisingly, this effect of AND on cortisol secretion (a stress hormone) was correlated with a reported increase in sexual arousal while viewing an erotic film and with a reduction in the negative mood otherwise seen in a control condition. In another study (Kovacs et al., 2004) heterosexual women were asked to rate men's faces for potential long vs. short term relationships, and while viewing the respective types of male faces they were asked to rate the pleasantness of a series of 5 different odorants, including AND. There was a significant correlation between women's rating of men's faces for long-term relationships and positive pleasantness ratings of AND. The authors argued that visual and olfactory (AND) cues interact to signal male reliability for long term romantic relationships. Another study (Saxton et al., 2008) studied the possible interaction between visual and cognitive attributes of men and AND signaling on women's ratings of male attractiveness in 3 different speed dating events. AND dissolved in a masking odor, clove oil, was applied to the upper lip as had been done in some earlier studies (Jacob et al., 2002; Jacob and McClintock, 2000) which sought to avoid any conscious perception of the presence of AND when it was presented. Application of AND, as opposed to clove oil alone or water, caused women (whose sexual orientation was not explicitly determined, although most were presumably heterosexual) to give men they encountered in 2 of the 3 speed dating events significantly higher attractiveness ratings. While not a uniformly positive outcome, these results further point to a possible AND-dependent facilitation of the effects of visual and other cognitive cues on women's perception of men as attractive romantic partners. A somewhat different outcome was obtained in another recent study (Parma et al., 2012) in which eye movements of heterosexual women were monitored while they viewed male or female faces or several different inanimate objects. Women that were studied during the preovulatory, follicular (potentially fertile) phase of the menstrual cycle showed maximal attention (viewing time) directed towards female faces (vs. male faces or inanimate objects), regardless of whether AND (dissolved in clove oil) or clove oil alone (control) was applied to the upper lip. By contrast, women studied during their luteal phase (low conception risk) preferred to watch female faces, provided they had received AND on the upper lip prior to the test. The authors argued that AND enhances intra-sex competition for mates, although their case would have been stronger had they found that the ability of AND to focus women's attention on potential competitors was highest during the fertile phase of the menstrual cycle.

\subsection{Sulfated metabolites of steroid hormones}

Several recent studies have identified sulfated metabolites of testosterone, estradiol, progesterone, and corticosterone, which are excreted as water-soluble compounds in the urine, as potent activators of VNO sensory neurons in mice. In an initial study
(Nodari et al., 2008) Holy and co-workers isolated several sulfated steroids from female mouse urine (BALB/c strain only) which strongly stimulated electrical activity in numerous VNO sensory neurons in both male and female mouse subjects. The range of sulfated steroids capable of activating VNO neurons represented all classes of steroid hormones that are produced in mice and other mammals. No sulfated steroids were detected in male BALB/c urine, raising the question of whether sulfated steroids provide a female-specific pheromonal signal to conspecifics. To date, no data have been provided to establish specific behavioral or neuroendocrine effects of female sulfated steroids in either sex. However, confirmation of the potent activational action of sulfated steroids on the murine VNO-accessory system has been provided in several more recent publications. Thus, Meeks et al. (2010) monitored electrical activity in both VNO sensory neurons and in AOB mitral cells of male mice exposed to any of 12 synthetic sulfated steroids including sulfated androgens, estrogens, pregnanolones, and glucocorticoids. Strong activation of VNO neurons was observed in response to each type of sulfated steroids. Most AOB mitral cells responded only to a single type of sulfated steroid, whereas the response of VNO sensory neurons was less specific. Finally, whereas sulfated estrogens strongly activated VNO neurons, little activation was seen in the AOB in response to this stimulus, perhaps pointing to an inhibitory effect in the VNO-AOB circuit. In a third study from the Holy lab (Turaga and Holy, 2012), female tetO-GCaMP2/ OMP-IRES-tTA mice that express the transgene only in MOE and VNO sensory neurons, together with objective-coupled planar illumination microscopy, were used to visualize a fluorescent calcium signal in thousands (as opposed to $<100$ neurons using conventional multi-electrode arrays) of VNO sensory neurons after the application of a variety of sulfated steroidal stimuli. These sulfated steroids activated consistent groups of $25-50 \%$ of all of the sensory neurons in the apical zone (abutting the lumen) of the VNO of male mice. Isogai et al. (2011) used expression of an immediate early gene, Egr1, as an index of VNO sensory neuron activation in CD-1 male mice, to monitor effects of sulfated steroids. Neurons in the apical VNO that express receptors of the V1R type showed reliable Egr-1 activation in response to several different sulfated steroids applied directly to the males' nares $40 \mathrm{~min}$ prior to sacrifice. VNO neurons expressing different subsets of V1R receptors were differentially activated by sulfated estrogens versus sulfated androgens or glucocorticoids. In another recent study using female mice (Celsi et al., 2012) several concentrations of different mixtures of sulfated sex and adrenal steroids stimulated calcium influx into isolated VNO sensory neurons. The results from these latter two papers are important because they represent a confirmation of the original Holy et al. reports from independent laboratories, using different methods for monitoring VNO neuronal activation. Questions remain, however, about which receptors expressed in VNO sensory neurons mediate the effects of sulfated steroids on neuronal activation and, indeed, whether sulfated steroids excreted in mouse urine exert any specific pheromonal actions in either sex.

\subsection{Estradiol and the Bruce effect}

When a recently mated female mouse is exposed a few days later to non-volatile urinary odors of a male from another strain, a pregnancy block ensues which is referred to as the Bruce effect, in recognition of the woman who discovered the phenomenon, Bruce (1959). No pregnancy block occurs in response to urinary odors derived from males of the mating partner strain, presumably because the female's accessory olfactory nervous system learns to recognize the source of these odors (Brennan, 2004; Halem et al., $2001 \mathrm{~b}$ ). The occurrence of pregnancy block in female mice is generally thought to depend on the detection and processing of urinary odors from strange males via the VNO-accessory olfactory 
system (Leinders-Zufall et al., 2004; Lloyd-Thomas and Keverne, 1982). An alternative hypothesis about the mechanism whereby urine from a strange male causes pregnancy block has been proposed by deCatanzaro and co-workers (Guzzo et al., 2012). These workers propose that estradiol excreted in the male's urine may be ingested nasally by females, such that the pumping mechanism whereby non-volatile odorants reach the VNO neuroepithelium (Meredith and O'Connell, 1979) propels male-derived estradiol into the female's blood stream. This circulating estradiol, in turn, would be conveyed to the uterus/fallopian tubes where it disrupts implantation of the blastocyst. Supportive evidence for this hypothesis involves several observations, including the fact that castration (which eliminates the source of aromatizable testosterone in males) blocks the ability of male urine to cause a Bruce effect (deCatanzaro et al., 2006) whereas removal of androgendependent preputial and coagulating glands has no such disruptive effect on the establishment of pregnancy in recently mated females (Zacharias et al., 2000). Also, tritium-labeled estradiol that was administered s.c. to male mice was excreted in the urine (Guzzo et al., 2010), and when administered into the nares of female mice was concentrated in the uterus. Measurable concentrations of unconjugated estradiol were detected in bladder urine of male mice, providing further support for the deCatanzaro hypothesis. A serious shortcoming of this hypothesis is the lack of a mechanism whereby males' strain identity could be encoded in urinary estradiol, whose chemical structure is invariable among different mouse strains and across vertebrate phylogeny. Likewise, if estradiol alone were responsible for inducing the Bruce effect, why would not contact with other females (another potential source of urinary estradiol) also cause pregnancy block? Clearly, even if it turns out that VNO-dependent ingestion of male-derived estradiol into the female's blood stream contributes to the Bruce effect, some additional sex and strain-specific, male signaling molecule must exist that plays a critical role in both the Bruce effect and in insuring that the urine of the mating male's strain does not cause pregnancy block. MHC peptides excreted in urine are candidate molecules for this role (Leinders-Zufall et al., 2004). More research will be needed to establish roles of either these MHC peptides and/or male-derived urinary estradiol in pregnancy block.

\section{Sex differences in the detection and processing of reproductive pheromones by the accessory olfactory nervous system}

The classic view is that sex differences in somatic morphology as well as in mammalian brain structure and/or function reflect either a difference in the adult, 'activational' effects of gonadal sex hormones in the two sexes and/or the perinatal, 'organizational' actions of testosterone secreted from the male's testes on developing somatic tissues or brain circuits (Baum, 1979; McCarthy and Arnold, 2011). Sex differences in the chemical composition of rat urine have been attributed to the presence in males of preputial glands, which are 'organized' during fetal life in response to the action of testosterone (Brouette-Lahlou et al., 1991). Lactating rat mothers spend more time displaying ano-genital licking of male vs. female pups in response to pheromones from the preputial glands that are incorporated into the male's urine (Moore and Samonte, 1986). This is one example of many different situations in which sex differences in/activational effects of sex hormones lead to differences in the production of pheromones. It has been claimed (Kimchi et al., 2007) that female mice (like males) normally develop the neural circuits that control the expression of male-typical mating behavior and that in adult females these circuits are tonically suppressed by VNO inputs, presumably because the female VNO has not been organized in a male-typical manner by the perinatal actions of testosterone. A more recent report (Martel and Baum, 2009a) disputes this conclusion by showing that simply administering testosterone to ovariectomized adult female mice activated a surprisingly high level of male-like mounting and pelvic thrusting behavior directed towards other females that were in estrus. This happened regardless of whether the VNO was intact or surgically removed in adult females, implying that the presence of VNO-dependent, pheromonal inputs was irrelevant to the level of male typical behavior displayed by females. Instead, a purely hormonal signal (testosterone) controls the expression of maletypical mounting behavior in this female rodent.

\subsection{Using Fos gene expression to study sex differences in the detection} and processing of pheromones throughout the olfactory systems

The early neuroanatomical research of Guillamon and Segovia (1997) established that the volumes of several subnuclei of brain regions that comprise the VNO-accessory olfactory projection circuit of rats (e.g., the medial amygdaloid nuclei; the bed nucleus of the stria terminalis; the medial preoptic area) are sexually dimorphic, with regional volumes being greater in males than in females. These sex differences in brain morphology are not easily explained by sex differences in circulating levels of sex hormones in adulthood. Instead, these sex differences most likely reflect the perinatal actions in the male of testosterone (acting as testosterone and/or via its neural metabolite, estradiol) (McCarthy and Arnold, 2011). Several early studies (Baum and Everitt, 1992; Kollack and Newman, 1992; Robertson et al., 1991) showed that mating in male rats and hamsters greatly augmented the expression of the immediate early gene, c-fos, in several segments of the accessory olfactory projection circuit to the medial preoptic area. Subsequent studies, carried out in several different mammalian species, used Fos gene expression as a reporter to study the ability of pheromonal stimuli to activate neurons included in the circuits of both the accessory and main olfactory systems. In an early report (Fiber and Swann, 1996) nasal contact with pheromones contained in vaginal sections from estrous female hamsters augmented Fos expression more robustly in the medial amygdala, bed nucleus of the stria terminalis, and medial preoptic area of male vs. female hamsters. This sex difference persisted even after adult gonadectomy and 'clamping' of circulating testosterone levels, implying that hard wired (perinatally determined) sex differences in a pheromone processing circuit exist in this species. A later study (Swann et al., 2001) implicated the main as opposed to the VNO-accessory olfactory pathway in this sexually dimorphic processing of vaginal pheromones in the hamster. The original study of Fiber and Swann (1996) failed to see any sex differences in the Fos responses to female vaginal secretions in either the main or accessory olfactory bulbs. More recent studies with mice (details below) have, however, identified sex differences in functional responses of VNO sensory neurons to a variety of pheromonal cues. It should be noted that in contrast to hamsters, male and female rats (both sexes were gonadectomized and treated with testosterone) showed equivalent Fos responses to pheromones emitted from soiled estrous female bedding at several levels of the olfactory projection pathway, including the AOB, posterior-dorsal medial amygdala, bed nucleus of the stria terminalis, and medial POA (Bressler and Baum, 1996). This outcome correlates with the noteworthy ability of female rats to display appreciable levels of female-oriented, male-typical mounting behavior in adult tests given following ovariectomy and testosterone treatment (Baum et al., 1974; Emery and Sachs, 1975). As already explained, a similar capacity was seen in normal female mice that were gonadectomized and treated with testosterone in adulthood (Bakker et al., 2002; Edwards, 1971; Martel and Baum, 2009a). 
In contrast to the absence of a sex dimorphism in Fos responses to estrous female pheromones, a robust sex difference was observed in Fos responses at several central segments of the olfactory projection pathway (e.g., BNST; mPOA) after exposure of gonadectomized, estradiol-treated adult male and female rats to soiled male bedding (Fig. 3) (Bakker et al., 1996). Importantly, an additional group of male rats that was treated neonatally with the aromatase blocking drug, ATD, later showed female-like Fos responses to soiled male bedding (Fig. 3). There were no effects of sex or male ATD treatment on the ability of male pheromones to augment Fos expression in the $A O B$, in agreement with previous studies in the hamster. These results suggest that the neural aromatization of testosterone to estradiol in the neonatal male rat brain normally defeminizes the olfactory circuit that processes male pheromones. A robust sex difference in the ability of pheromones found in soiled male bedding to augment Fos expression in the BNST and mPOA has also been obtained in the ferret (Kelliher et al., 1998) and mouse (Bodo and Rissman, 2007; Halem et al., 1999) while gonadectomized subjects were treated in adulthood with testosterone and estradiol, respectively. Male mice with the spontaneous testicular feminization mutation (which disrupts expression of the androgen receptor throughout the body) showed a female-typical profile of Fos expression in the MPOA and BNST (Bodo and Rissman, 2007). The authors concluded that in mice (unlike rats) the perinatal actions of testosterone that defeminize the olfactory circuit that processes male pheromones do not depend on the estrogenic metabolites of this testicular steroid, but instead on the action of testosterone itself, acting upon neurons that express androgen receptors. This is confirmed by observations in estrogen-deficient male aromatase knockout (ArKO) mice which showed a normal, male-typical expression of Fos following exposure to male pheromones (Pierman et al., 2008).

\subsection{Sex differences in $\mathrm{VNO}-\mathrm{AOB}$ responses to pheromones}

Two separate families of seven-transmembrane receptors have been identified in the mouse VNO (Dulac and Axel, 1995) with the V1R family being expressed in the apical VNO sensory neurons

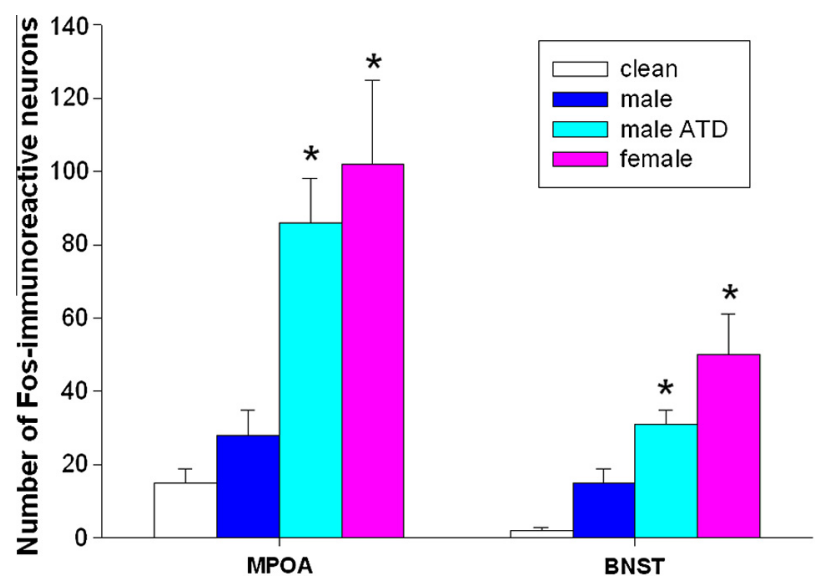

Fig. 3. Neonatal treatment of male rats with the aromatase inhibiting drug, ATD caused them to show a female-like profile of Fos expression in the medial preoptic area (mPOA) and the bed nucleus of the stria terminalis (BNST) after exposure to soiled male bedding pheromones in adulthood. 'Clean' = clean bedding control condition (group was comprised of 2 rats from each of the other 3 treatment conditions). The other three groups were exposed to soiled male bedding prior to sacrifice. All rats were gonadectomized in adulthood and administered estradiol prior to odor exposure and sacrifice $1.5 \mathrm{~h}$ later. Data are expressed as means \pm SEM. " $p<0.05$ comparisons with both the male group exposed to male pheromones and with the clean bedding control group. Adapted with permission from tabular data presented in Bakker et al. (1996). that abut the VNO lumen and the V2R family being expressed in the basal zone of the VNO (receptor neurons in the two zones co-express different $G$ proteins). An early study (Herrada and Dulac, 1997) reported a complex profile of sex differences in the expression of VNO receptor genes in both the V1R and V2R families of putative pheromone receptors. No statistical analyses were carried out on the data reported, thus it is difficult to draw definitive conclusions from them. Another study (Matsunami and Buck, 1997) found no sex differences in the expression of V2R VNO receptor genes in mice; however, both this study and the one by Herrada and Dulac (1997) employed gonadally intact male and female rats. This practice makes it impossible to reliably assess the contribution of adult circulating sex hormones vs. hard-wired sex differences in neuronal characteristics resulting from differences in the perinatal actions of testosterone between the two sexes. More recently, a systematic analysis using in situ hybridization of representative gene mRNAs from the V2R family (VR1 and VR4) was carried out using male and female mice that were gonadectomized in adulthood and given either no hormone, testosterone, or estradiol for several weeks prior to sacrifice (Alekseyenko et al., 2006). In the absence of any hormone replacement, expression of the VR1 gene was significantly greater in males than in females, and adult treatment with either estradiol or testosterone tended to reduce its expression. The ability of steroid hormones to modulate VNO receptor gene expression was not linked to the expression of either estradiol receptor-alpha or of androgen receptor in VNO sensory neurons (Alekseyenko et al., 2006). It seems likely that a centrifugal signaling pathway allows adult sex hormones to modulate VNO receptor gene expression. Perhaps perinatal exposure of males to testosterone or its metabolites masculinizes this yet-to-be identified centrifugal pathway.

Studies already reviewed show that the ability of male pheromones to activate the VNO-AOB-accessory olfactory pathway differs in the two sexes and is affected by adult exposure to sex hormones. One early study (Halem et al., 1999) asked whether VNO sensory neurons themselves show sex differences in responses to pheromones emitted from soiled bedding. The expression of Fos in basal zone VNO sensory neurons in response to male bedding pheromones was significantly higher in gonadectomized female vs. male mice, and treatment with estradiol greatly amplified the magnitude of this sex difference (Fig. 4). There were no consistent effects of sex or estradiol treatment on the number of Fos-ir granule or mitral cells in the AOB following exposure to soiled male bedding. The former result was extended in a study (Halem et al., 2001a) in which the expression of another immediate early gene, Egr-1, in the VNO basal zone was found to be significantly greater in female than in male mice that were gonadectomized in adulthood and given estradiol prior to being exposed to male bedding. Again, the respective AOB responses to this stimulus did not differ between estradiol-treated females and males. There was no sex difference in other gonadectomized, estradiol-treated mice that were exposed to female instead of male bedding, nor was the AOB Fos response to female bedding different between these latter two groups. In a study (Holy et al., 2000) in which electrical responses were recorded from a large number of VNO sensory neurons it was found that application of either male or female urine augmented activity in a diffuse population of VNO neurons from both sexes, although systematic statistical comparisons of results for the two sexes were not carried out. In another study (Leinders-Zufall et al., 2000) confocal calcium imaging was used to map responses to several putative male urinary pheromones in VNO slices taken from female mice. Unfortunately, no manipulations of females' sex hormone status were carried out, and male VNO slices were not studied. More recently, He et al. $(2008,2010)$ studied the ability of male vs. female urinary odors to elevate intracellular calcium (an index of VNO receptor 

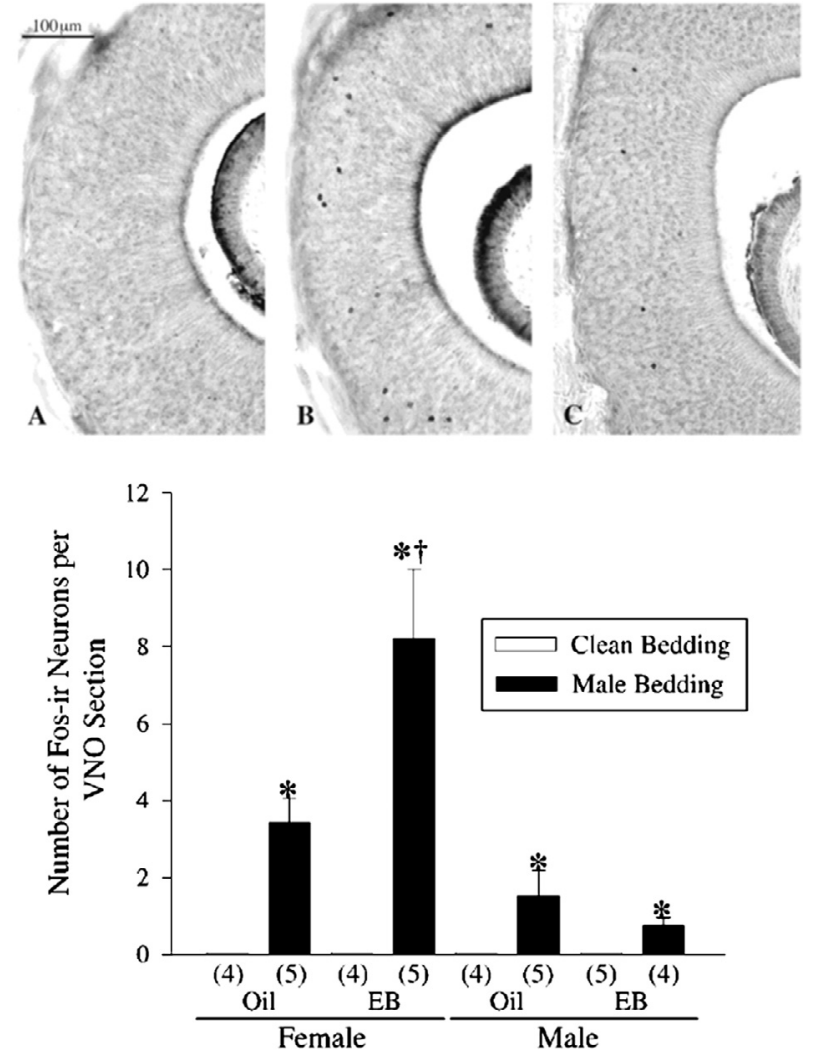

Fig. 4. Exposure to soiled male bedding pheromones stimulated Fos expression in vomeronasal sensory neurons more strongly in ovariectomized female than in castrated male mice while both groups received estradiol benzoate (EB) as opposed to the oil vehicle (oil) for EB. Upper panels: Photomicrographs showing Fos staining in the vomeronasal neuroepithelium of $(\mathrm{A})$ an EB-treated female exposed to clean bedding, (B) an EB-treated female exposed to soiled male bedding odors, and (C) an EB-treated male exposed to soiled male bedding odors. Lower panel: ${ }^{*} p<0.05$ comparisons with same sex/hormone treatment groups exposed to clean bedding instead of soiled male bedding. Data are expressed as mean \pm SEM; group sizes are given in parentheses. $+p<0.05$ comparisons with each of the other groups that were also exposed to male bedding. Adapted with permission from figures shown in Halem et al. (1999).

activation) in VNO slices taken from male and female transgenic mice that expressed the calcium indicator, G-CaMP2. Although no actual data comparing male and female VNO slices were presented, the authors asserted that there was no sex difference in VNO responses to urine when applied to the slices. Female urine activated a larger population of VNO neurons than did male urine, and urine from different strains/individuals was reportedly encoded by the differential activation of different combinations of VNO sensory neurons. Also, increasing concentrations of urine activated increasing numbers of VNO sensory neurons. In the absence of any systematic presentation of data from male vs. female VNOs and in the absence of any effort to manipulate the adult sex hormone status of subjects, these otherwise elegant studies shed little light on the question of whether there are either organizational or activational effects of testosterone (or estradiol) on mouse VNO function.

In an early study (Luo et al., 2003) electrophysiological recordings were made in the AOB of male mice as they interacted with conspecifics of both sexes of the same vs. different strains. Importantly, AOB responses were seen only when males made nasal contact with either the ano-genital or facial regions of conspecifics. No responses to volatile odorants (including putative volatile pheromones) were seen. When they did occur, AOB responses were tuned to the sex and genetic background of these conspecifics. Again, however, no sex comparison or analysis of the contribution of activational sex hormones to the responsiveness of AOB neurons was carried out in this otherwise groundbreaking study. More recently, Ben-Shaul et al. (2010) developed an anesthetized mouse preparation in which pheromonal stimuli could reliably be delivered to the VNO sensory neurons by electrically activating the VNO pump. Recordings were taken from a multi-electrode array inserted into the ipsilateral AOB mitral cell layer. In agreement with Luo et al. (2003) and Ben-Shaul et al. (2010) confirmed that differential AOB responses were seen to male vs. female urine or saliva. Interestingly, predator urinary odors also reliably activated AOB mitral cells. Although the authors used both male and female Balb-C mice in their experiments, no systematic sex comparisons or analysis of potential, activational effects of circulating sex hormones were carried out in this study.

\section{Sex differences in the detection and processing of reproductive pheromones by the main olfactory nervous system}

\subsection{Sex differences in the activation of the $A O B$ by volatile pheromones acting via a centrifugal pathway}

As already stated, no systematic differences were found between male and female mice in the ability of soiled male (or female) bedding (which is supposed to consist primarily nonvolatile odors) to elicit Fos responses in either the granule or mitral cell layers of the AOB (Halem et al., 2001a, 1999). More recently a small subset of MOB mitral cells was identified that extend axons directly to the medial amygdala (both the anterior and posteriordorsal subdivisions) (Kang et al., 2009). Similar results have been obtained in the rat in which MOB mitral cells targeting both the medial amygdala (Pro-Sistiaga et al., 2007) and the AOB itself (Larriva-Sahd, 2008) have been identified. In mice the MeA projecting MOB mitral cells also extend axon collaterals to a wide expanse of targets in piriform cortex (Kang et al., 2011a; Sosulski et al., 2011). These MOB mitral cells in females expressed Fos selectively in response to volatile urinary odors from male, but not female conspecifics (Kang et al., 2009). The existence of a population of MOB mitral cells that target the MeA explained the previous observation (Martel and Baum, 2007) that exposure to urinary volatiles stimulated robust Fos responses in both the granule and mitral cells layers of the AOB of opposite-sex mice (Fig. 5). Thus in ovariectomized female subjects (given no sex hormones), male but not female urinary volatiles stimulated Fos expression in both granule and mitral cells of the AOB (Fig. 5 top panel), and in castrated male mice (also given no sex hormones) female but not male urinary volatiles stimulated Fos expression in both AOB layers (Fig. 5 bottom panel). In subjects of both sexes, intranasal pre-treatment with the toxin, zinc sulfate (which destroyed MOE sensory neurons), blocked the ability of opposite-sex urinary volatiles to stimulate AOB Fos responses. A follow up study using female subjects with zinc sulfate lesions of the MOE showed that AOB Fos responses to nasal application of male urine persisted. Taken together, these results strongly suggest that AOB Fos responses to urinary volatiles occur after their detection by the MOE and processing via the MOB. These results challenge the existing dogma that pheromonal inputs to the AOB originate only in VNO sensory neurons.

In an attempt to identify the pathway whereby volatile pheromones detected by MOE sensory neurons gain access to the AOB, it was found (Martel and Baum, 2009b) that centrifugal inputs from the MeA to the AOB convey the inputs that originated with opposite sex urinary volatiles detected by the MOE. It is especially noteworthy that the striking sex difference in the ability of male as well as female urinary volatiles to activate AOB Fos (only oppositesex pheromones were effective) occurred in mice that had been 

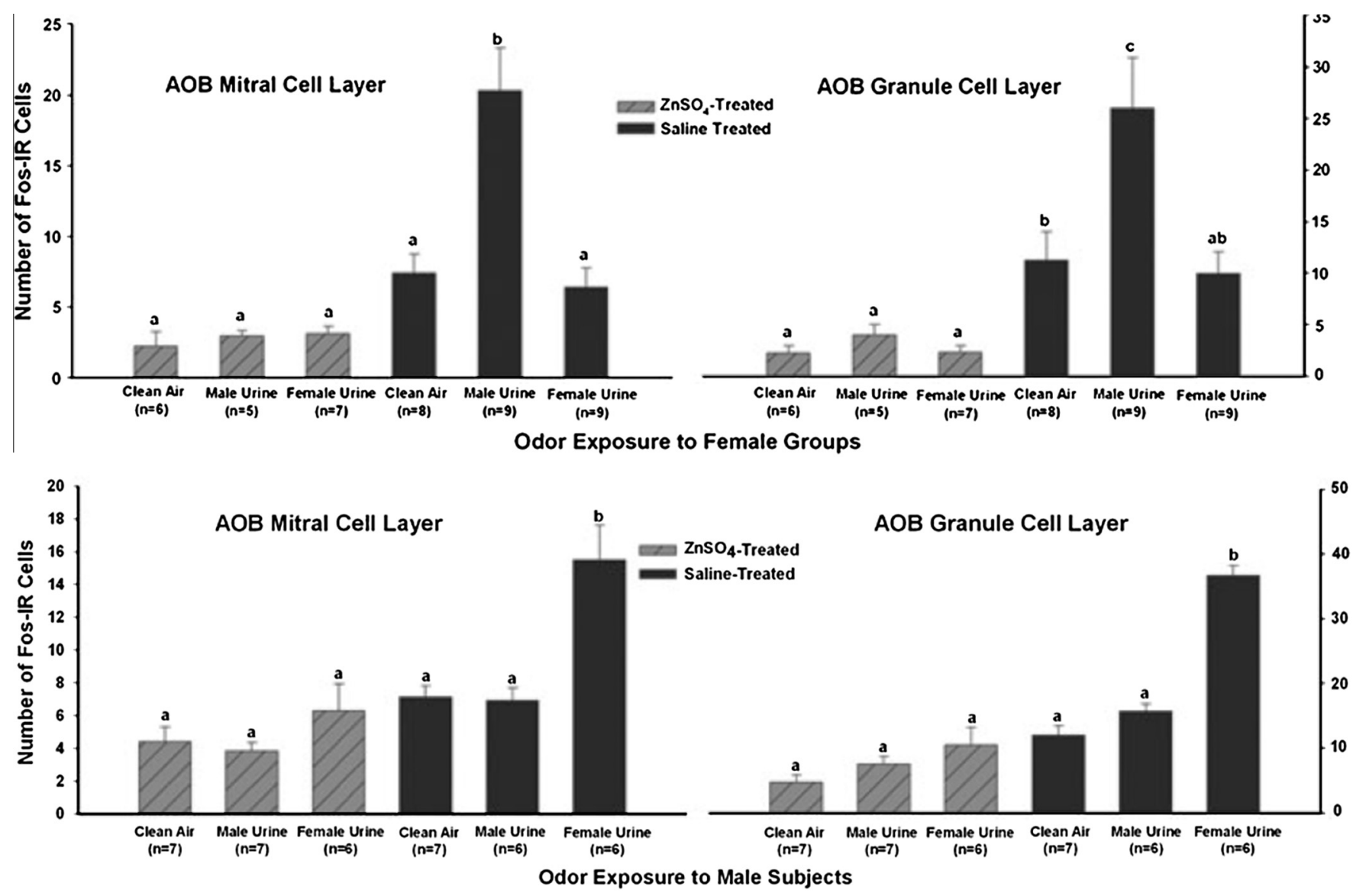

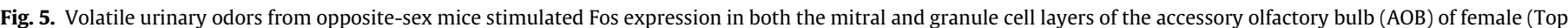

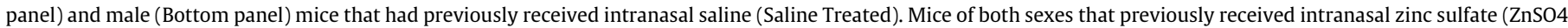

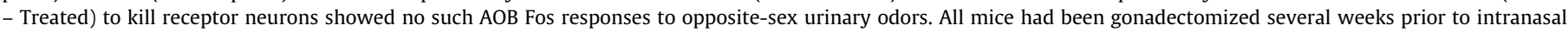

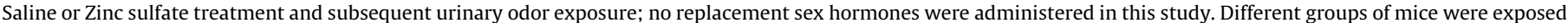

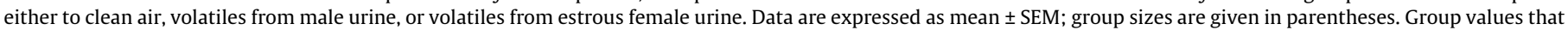
differed significantly from each other have different letters listed above each data bar. Adapted with permission from data published in Martel and Baum (2007).

gonadectomized and given no sex hormones for several weeks. In the absence of any activational sex hormones, these results point to a hard-wired sex difference in the responsiveness of the main olfactory system to volatile urinary pheromones. Whether these observed differences depend on sex differences in the expression of MOE receptor genes and/or in sex differences in the anatomy and/or functional responses of neurons in this circuit (e.g., MOB juxtaglomerular, granule, and/or mitral cells; MeA neurons that target the AOB mitral and granule cell layers) remains to be determined. Recently, one of us (MJB and colleagues) have begun studying a transgenic mouse (Nakajima et al., 2001; Tye and Deisseroth, 2012) in which the excitatory cation channel, channelrhodopsin, can be selectively expressed in MOB or AOB mitral cells of male and female mice. It will be interesting to determine whether selective optogenetic activation of mitral cells in the MOB vs. AOB that target the medial amygdala can mimic the effects of same vs. opposite sex pheromones on electrophysiological responses of the MeA or on behavioral responses (e.g., preference for a place previously associated with pheromones from the same vs. opposite sex) in male vs. female subjects.

\subsection{Sex differences in the detection and processing of volatile pheromones}

\subsubsection{Sex differences in forebrain regions}

The Fos responses to male vs. female urinary volatiles in different forebrain regions of ovariectomized female mice (Martel and
Baum, 2007) resembled the sex difference in Fos responses to soiled bedding already described, above (Bodo and Rissman, 2007; Halem et al., 1999; Pierman et al., 2008). Thus, male, but not female (same-sex), urinary volatiles augmented Fos expression in the BNST and MPOA of ovariectomized female mice given no ovarian hormones, with a parallel (non-significant) trend being seen in the medial amygdala. This effect was absent in other females in which MOE olfactory receptor neurons had previously been destroyed with zinc sulfate. It is noteworthy that in a subsequent study (Kang et al., 2009) exposure to urinary volatiles from male, but not female, conspecifics stimulated Fos expression robustly at all levels of the forebrain olfactory projection circuit, including the medial amgydala, BNST, mPOA and ventromedial hypothalamus. This latter study was carried out using ovariectomized female mice that received estradiol followed by progesterone (mimicking the sex hormone profile of the night of proestrus). The stronger male-pheromone induced Fos responses in ovariectomized females given ovarian hormones vs. no hormone replacement points to a likely activational effect of these hormones on the olfactory processing of volatile urinary pheromones. Whereas females showed forebrain Fos responses only to male urinary odors, in castrated male mice exposure to either male or female urinary volatiles augmented Fos expression in subnuclei of the medial amygdala as well as in the BNST and MPOA (Martel and Baum, 2007). More recently, it was found (Kang et al., 2011b) that as in the female mouse, males possess a population of MOB mitral cells that extend axons directly to the medial 
amgydala. MOB mitral cells in male mice that were retrogradely labeled by injection of cholera toxin into the medial amygdala showed augmented Fos co-expression after exposure to male (same-sex) urinary volatiles. This outcome contrasts with results obtained in female mice (Kang et al., 2009) in which female (same-sex) urinary volatiles failed to stimulate co-expression in MOB mitral cells that were retrogradely labeled by cholera toxin injected previously into the MeA. Presumably, opposite sex, female urinary volatiles would also stimulate Fos in MeA-projecting MOB mitral cells of males, although we have not yet confirmed this outcome. Future studies using optogenetics will determine whether sex differences in as well as upregulation by sex steroids of forebrain Fos responses to the same volatile urinary pheromones reflect effects of sex and/or sex steroids at the level of the MOB.

\subsubsection{Sex differences in the MOE-MOB projection}

Whereas sex differences in and activational effects of adult sex hormones on the expression of VNO receptor proteins have been reported (Alekseyenko et al., 2006; Herrada and Dulac, 1997), no such effects of sex or sex steroids on the expression of olfactory receptor proteins in the MOE have been reported. As with the VNO, no studies have reported the expression of estradiol and/or androgen receptors in the MOE. Two early studies (Pfaff and Gregory, 1971; Pfaff and Pfaffmann, 1969) compared the ability of urinary volatiles from female rats (estrous vs. ovariectomized females) to activate electrical activity in the MOB (specific locations/cell types were not specified) and medial POA of castrated vs. testes-intact male rats. Female odors stimulated higher activity in the MPOA than in the MOB of males. However, there was no notable effect of castration (or of testosterone replacement) on the level of activity in either the MOB or MPOA of males exposed to either type of female urinary volatiles. In this context it is worth noting that the population of MOB mitral cells that extend axons to the medial ('vomeronasal') amygdala, which presumably convey pheromonal inputs to this structure, invariably extend axon collaterals widely over the piriform cortex (Kang et al., 2011a). More research is needed to determine whether cortical processing of pheromonal inputs occurs in parallel with processing in the MeA and whether such parallel processing influences the perception of or behavioral reactions to particular pheromones.
Restrepo and co-workers developed a method for using odorstimulated Fos expression in juxtaglomerular interneurons of the MOB to map the distribution of glomeruli that were activated by particular volatile pheromones (Schaefer et al., 2002, 2001). We have applied this method to ask whether a sex difference can been seen in the pattern of MOB glomerular activation shown in response to male or female urinary volatiles (Martel and Baum, 2007). As is shown in Fig. 6, 'hot spots' of glomerular activation were seen in the ventral MOB that stretched across the rostralcaudal extent of this structure after exposure to either male or female urinary volatiles in both sexes. Within each sex, the location of hot spots of glomerular activation appeared to be very similar after exposure to either male or female urinary vapors. However, the rostral-caudal extent of maximal glomerular activation appeared to be consistently greater in female (Fig. 6; top row panels A, B and C) than in male (Fig. 6; bottom row panels) subjects, regardless of whether they were exposed to male or female urinary volatiles. Recall that all mice in this study had been gonadectomized as adults and given no sex hormones prior to sacrifice several weeks later. Thus, this sex difference may be hard wired by perinatal actions of testosterone in the male. Interestingly, a parallel sex difference (female $>$ male) in glomerular activation on the surface of the MOB was observed using calcium imaging in gonad-intact mice that were exposed to a non-pheromonal odor, butyl acetate (J. McGann, personal communication). More research is needed to determine whether perinatal and/or adult sex differences in sex hormone actions contribute to this latter sex difference. More work will also be needed to specify the existence (and origin of) sex differences and adult hormone effects on both the peripheral and central processing of pheromones in both the main and accessory olfactory circuits.

\section{Sex differences in behavioral indices of reproductive pheromone detection and sexual partner preference}

\subsection{Sex differences in pheromone detection thresholds}

As already explained, the volatile androgen, androstenone, serves as a male pheromone in pigs. Thus ovary-intact female pigs were able to detect lower concentrations of this steroid than

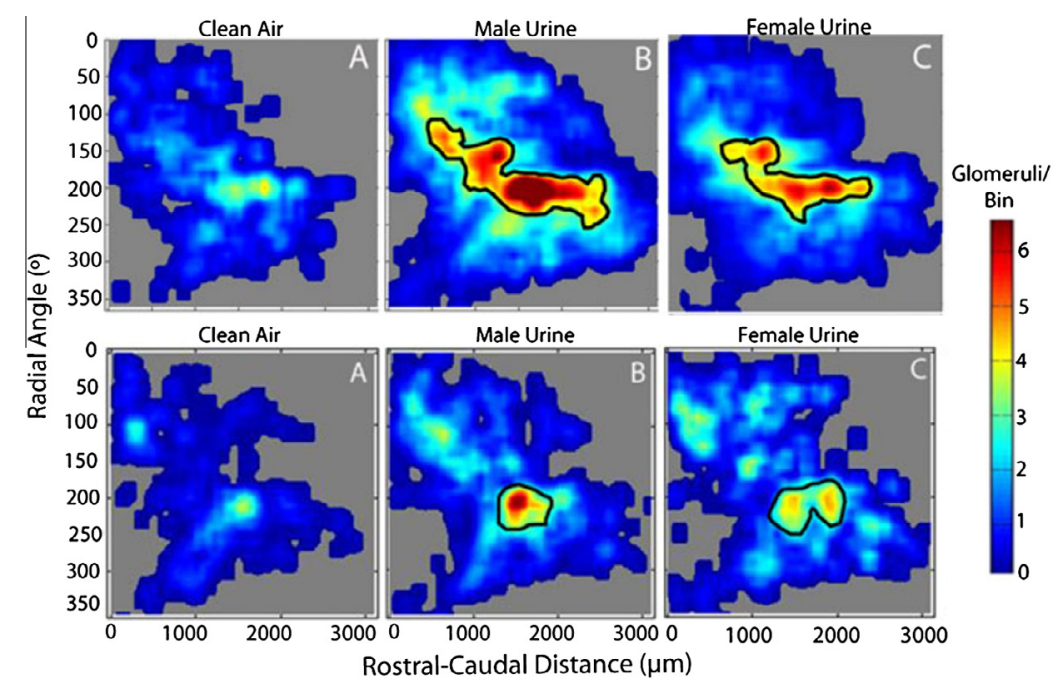

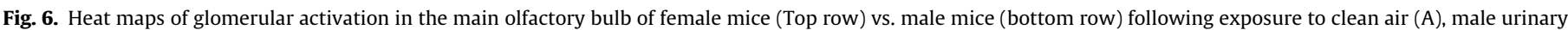

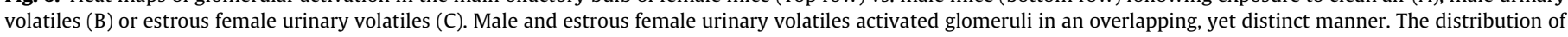

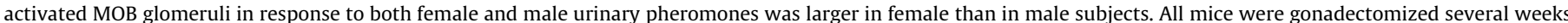

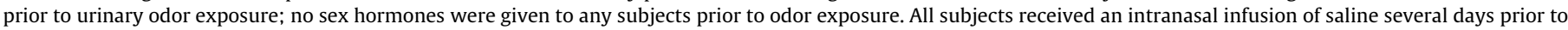
the urinary odor exposure (control subjects from Fig. 4). Adapted with permission from data published in Martel and Baum (2007). 
testes-intact males in a hunger-motivated operant task (Dorries et al., 1995). The design of this study made it impossible to decide whether the observed sex difference in androstenone detection threshold reflected differences in adult circulating sex hormones or a hard-wired sex difference. In a related study (Baum and Keverne, 2002), the ability of mice to show dishabituation responses to the initial introduction of increasing dilutions (decreasing concentrations) of volatile male urinary pheromones was used to look for a sex difference in pheromone detection capacity (Fig. 7). Hybrid CBA/C57Bl6 mice that had been embryo transferred to pseudopregnant DBA mothers (newborn offspring were also reared by these same mothers) were used as subjects in order to avoid having had them be exposed to pheromones from the paternal (C57) bl6) strain. A range of different concentrations of urine from males of this strain was used to assess detection thresholds in male vs. female mice which were gonadectomized at 3 months of age and given no replacement sex hormones. Behavioral tests began when mice were 5 months old. We avoided giving sex steroids to our gonadectomized subjects at the time of behavioral testing because pilot work had shown that hormone-free mice could perform this task. Thus any sex differences seen in detection thresholds would presumably reflect the developmental organization of hard-wired, sexually dimorphic circuits that were independent of any interacting adult, activational effect of sex hormones. Olfactory stimuli (water as well as increasing dilutions of C57Bl6 male urine) were presented in subjects' home cages on pieces of filter paper

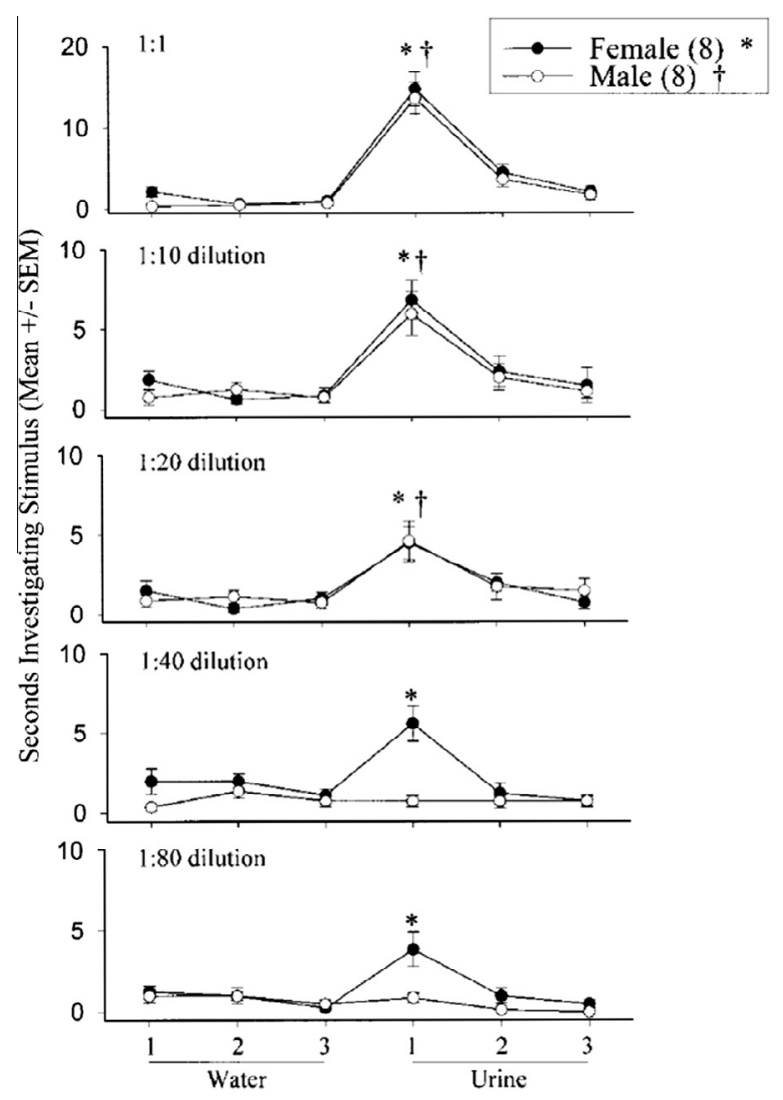

Fig. 7. Female mice were better able than male subjects to detect low concentrations (urine:water dilutions of 1:40 and 1:80) of male urinary volatiles. Data shown are investigation times displayed in home cage tests by mice towards a dilution series of male urine spots (no nasal contact was allowed, thus only volatiles were detected). Stimuli (water or urine) were presented consecutively for $2 \mathrm{~min}$. (1 $\mathrm{min}$ intervals between presentations). All mice had been gonadectomized (and not given any sex hormones) 2 months prior to behavioral testing. ${ }^{*}+p<0.05$ comparisons with the previous presentation (number 3 ) of water. The number of subjects is given in parentheses. Reproduced with permission from Baum and Keverne (2002) positioned behind a wire mesh to avoid direct nasal contact with the stimulus. As shown in Fig. 7, both male and female subjects readily showed a significant dishabituation response to undiluted (1:1) male urine as well as to urine dilutions of $1: 10$ and $1: 20$ when it was first presented following successive presentations (at $3 \mathrm{~min}$. intervals) of water. Females, but not males, continued to show dishabituation responses to the initial presentation of $1: 40$ and 1:80 dilutions of male urine. Similar results were also obtained by Pierman et al. (2006). The observed sex difference in detection thresholds (females more sensitive than males) cannot be explained by differences in activational sex steroid actions at the time of testing since subjects had all been gonadectomized (and given no replacement hormones) more than 2 months earlier. Instead, we suggest that a hard-wired sex difference in the perception of male urinary volatiles exists, which correlates with the larger MOB glomerular response to male as well as female urinary volatiles shown in Fig. 6. A similar sex difference (females more sensitive than males) was seen in the detection thresholds of gonadectomized mice when exposed to urinary volatiles from estrous female mice (Baum and Keverne, 2002), which again correlated with larger MOB glomerular responses to this stimulus in females vs. males. It seems unlikely that early experience with either male or female urinary pheromones from the $\mathrm{C} 57 \mathrm{Bl} / 6$ inbred strain contributed to the sex differences observed in so far as subjects' first encounter with urinary volatiles from this particular strain occurred at the onset of the tests shown in Fig. 7. Evidence of an organizational contribution of estradiol to a defeminization of olfactory detection capacity in male mice comes from the observation (Pierman et al., 2006) that ArKO male mice successfully detected lower concentrations of both male and estrous female urinary volatiles than WT control males in habituation/dishabituation tests. Evidence of an activational contribution of sex steroids to the performance of male and female mice in such habituation/ dishabituation tests comes from the observation that administering testosterone, but not estradiol or dihydrotestosterone, significantly increased the ability of gonadectomized mice of both sexes to detect low concentrations of either male or estrous female urinary volatiles (Pankevich et al., 2003).

The use of habituation/dishabituation tests to carry out a sex comparison of pheromone detection (Fig. 7) relies on the intrinsic interest of subjects to investigate urinary volatiles from conspecifics. As a result, it is difficult to argue, conclusively, that the observed sex difference in detection thresholds reflected a sex difference solely in the function of the olfactory processing circuit vs. a sex difference in the motivational circuits that drive the investigative behavior used to assess olfactory capacity. In an attempt to avert this dilemma, we conducted an experiment (Sorwell et al., 2008 ) in which the ability to use decreasing concentrations of male urinary odor to locate food (a piece of cherrio) buried in one of two adjacent sand piles was compared in male vs. female mice maintained at $85 \%$ of their original body weight. All mice were gonadectomized 2 weeks prior to the onset of behavioral testing so that uncontrolled sex differences in circulating gonadal sex hormones would not influence the outcome of this study. As shown in Fig. 8, there was a progressive decline in the ability of gonadectomized mice of both sexes to successfully locate the food reward as the concentration of the urinary odor signaling the location of food was decreased. In the absence of any hormone administration, the response profile across a declining range of urine concentrations was equivalent in the two sexes. This outcome differed from the studies (Baum and Keverne, 2002; Pierman et al., 2006) using a habituation/dishabituation paradigm in which females continued to respond longer than males to progressively lower concentrations of male urinary odors. As shown in Fig. 8, when gonadectomized females were treated daily with estradiol benzoate (EB), their performance on the pheromone-signaled food finding task 


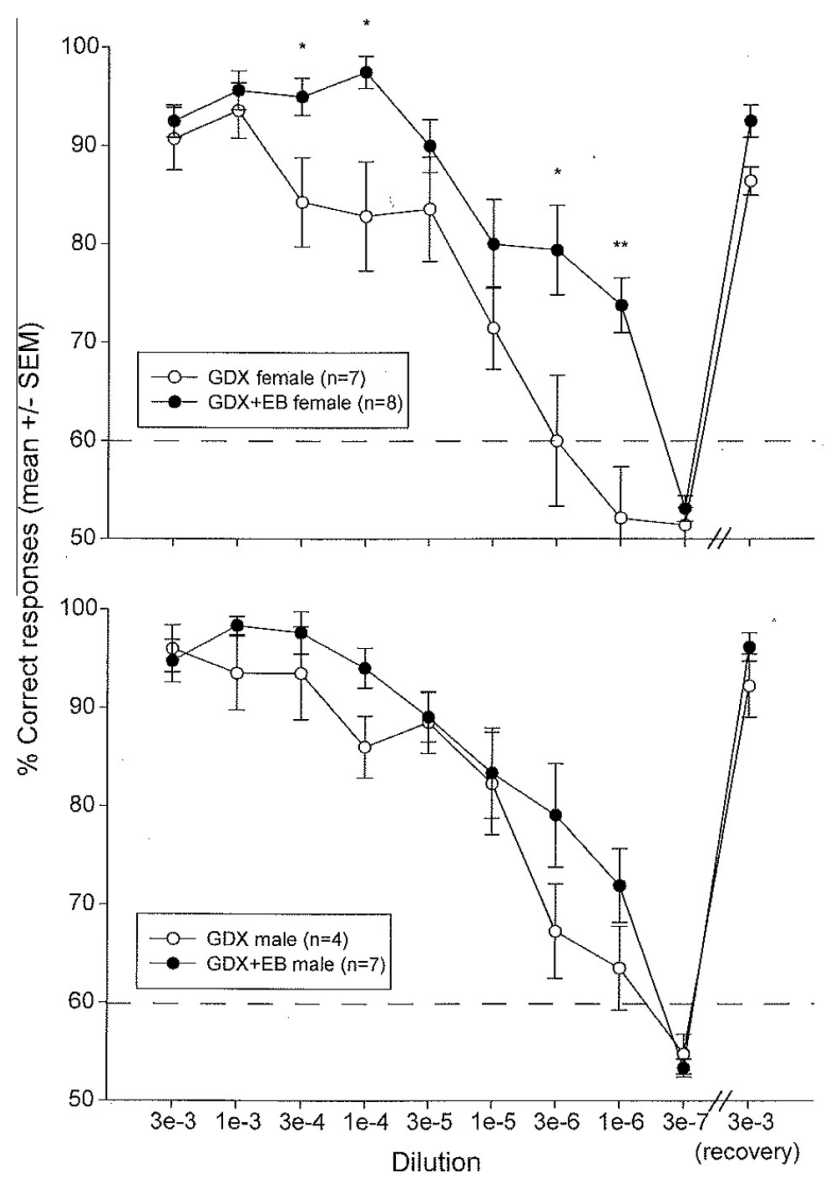

Fig. 8. Gonadectomized (GDX) male and female mice maintained on a food deprivation schedule were trained to use progressively lower concentrations of urinary odors from testes-intact male mice as a discriminatory stimulus to locate a food reward. In the absence of any hormone treatment (open circles), females (top panel) and males (bottom panel) showed equivalent detection thresholds for progressively lower concentrations of urinary odors. However, in response to daily injections of estradiol benzoate (EB), the same females showed a significant improvement in odor detection performance (top panel) whereas no effect of EB was seen in males (bottom panel). The dashed line at $60 \%$ represents the performance criterion below which subjects were deemed as having failed to detect the urinary odor concentrations presented. ${ }^{*} p<0.05,{ }^{* *} p<0.01$, two-tailed between groups t test comparisons of GDX females' odor detection performance with and without EB treatment. The number of mice tested under each endocrine condition is shown in parentheses. Reproduced with permission from Sorwell et al. (2008).

was significantly improved over the prior response profile established in the absence of hormone replacement. By contrast, no such improvement occurred in gonadectomized males when they were given EB. Thus when an activational sex hormone, estradiol, was administered to gonadectomized mice, a robust sex difference (females > males) in subjects' ability to detect male urinary odors was observed. In so far as this task was motivated by hunger instead of an intrinsic interest in urinary odors, it seems likely that the observed sex difference in detection threshold reflected a sex difference in the function of the olfactory nervous system. It was likely that the main, as opposed to the accessory, olfactory system allowed subjects to acquire the task in so far as nasal contact with the substrate was not required for mice to make a correct position choice of the male urine-odor baited food source. An interesting correlate of the observed EB-induced improvement in females' olfactory detection capacity was a significant reduction in sniff frequency (monitored by intranasal pressure measurements) which was greatest when females were presented with very low concentrations of male urinary odors (Sorwell et al., 2008). Two more
Intact male urine $\left(\mathrm{S}^{+}\right)$

$E+P$-female urine (S-)

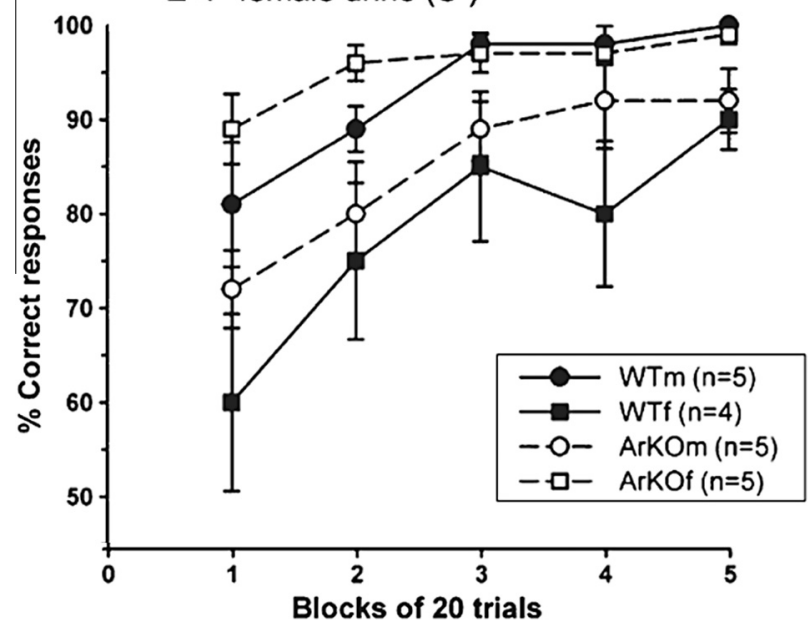

Fig. 9. Gonadectomized, estradiol-treated wild type (WT) and aromatase knock out (ArKO) male ( $\mathrm{m}$ ) and female ( $\mathrm{f}$ ) maintained on a food deprivation schedule were trained in a 'go, no-go' task over a series of trials to discriminate between male and estrous female urinary volatiles. WT females performed better than WT males; ArKO females performed better than WT females and ArKO males performed worse than WT males on this discrimination task. Urinary vapors from testes-intact males signaled that a food reward was available (S+). Urinary vapors from estrous females (ovariectomized females given estradiol followed by progesterone; $\mathrm{E}+\mathrm{P}$ ) signaled that food was not available (S-). Data are expressed as mean \pm SEM; group sizes are given in parentheses. Adapted with permission from Wesson et al. (2006).

recent studies by one of us (JB) showed that estradiol either had no effect (Veyrac and Bakker, 2011) or reduced (Brock et al., 2010 b) cell proliferation in the subventricular zone, with resultant modulation of the incorporation of new granule cells into the MOB. More research is needed to assess the possible contribution of newly born neurons to the increased pheromone detection capacity resulting from estradiol treatment in females.

\subsection{Sex differences in pheromone discrimination capacity}

In another study (Wesson et al., 2006) we used a 'go/no go' task with a liquid olfactometer to compare the ability of male and female mice of different genotypes (details below) to discriminate between urinary volatiles obtained from mice of different sexes/ adult gonadal status. All subjects were gonadectomized in adulthood and given daily injections of EB at the time of behavioral testing, thus any observed group differences in urinary odor discrimination capacity could not be attributed to differences in adult circulating sex steroids. We avoided testing gonadectomized mice given no steroids in this food motivated task in light of an early report (Doty and Ferguson-Segall, 1989) that the ability of male rats to perform a similar go/no go task involving perception of different concentrations of ethyl acetate was attenuated after castration. A similar deficit was seen in a pilot study (D. Wesson, unpublished results) using gonadectomized male and female mice given no steroids. The task required food-deprived subjects to sniff an odor port that delivered a volatile urinary odor (air blown over a 1:100 dilution of urine) emitted from a testes-intact male mouse (which cued the availability of liquid food) vs. an ovariectomized female primed with estradiol and progesterone (estrous female; which cued the non-availability of liquid food). As shown in Fig. 9, wild type male mice (WTm) acquired this discrimination significantly more rapidly than wild type females (WTf).

A large literature (McCarthy and Arnold, 2011) has implicated estradiol, formed via the neural aromatization of testosterone 
secreted perinatally from the testes, in brain sexual differentiation of male rodents, including mice. Likewise, recent work (Brock et al., $2011,2010 a$ ) also implicates estradiol, secreted prepubertally from the ovaries, in brain and behavioral sexual differentiation of female rodents. We therefore asked whether knocking out the Cyp 19 gene, which encodes aromatase, would disrupt the capacity of either male or female mice to discriminate between male and estrous female urinary volatiles. Females that lacked aromatase expression (ArKO) across development (recall that all mice received exogenous EB at the time of adult testing) were significantly better than WT control females in discriminating between male and female urinary odors. The performance of ArKO females resembled that of WT males, with ArKO males being only slightly less capable than WT males (not significantly so) in making this odor discrimination. While estradiol, formed perinatally via the neural aromatization of testosterone in the developing male rodent has been implicated in the differentiation of neural circuits that control male mating behavior (McCarthy and Arnold, 2011), the absence of consistent differences between WT and ArKO males in urinary discrimination capacity suggest that estradiol acting in the male is not the primary determinant of the observed sex difference in the ability of WT mice to discriminate male vs. female urinary odors. Instead, our results raise the possibility that estradiol acts across development in WT females to defeminize the capacity to discriminate between male and female urinary odors. The enhanced olfactory discrimination capacity of ArKO (compared with WT) female mice was even more evident when subjects were given food reward for discriminating between urinary odors of ovariectomized female mice that either received estradiol alone vs. estradiol + progesterone (Wesson et al., 2006). These two types of urinary odors induced very similar profiles of glomerular activation (indexed using Fos expression in periglomerular neurons) in both WT and ArKO females (Martel and Baum, 2007), implying that the observed genotype differences in odor discrimination capacity likely reflected differences in the processing of these odors at more central segments of the main olfactory pathway. More research is needed to specify sites in the olfactory pathway where estradiol might exert its organizing action in the developing female.

\subsection{Sex differences in sexual partner preference: contribution of pheromones}

Numerous studies (Brown, 1977; Carr et al., 1966; Ferkin, 1992; Nyby et al., 1977), usually carried out in rodent species, showed that mammals reliably choose to approach and investigate pheromonal cues from an opposite-sex, as opposed to a same-sex, conspecific. Typically, these sex-specific odor preferences are only expressed during the breeding season, in the presence of circulating testosterone (males) or ovarian steroids (females). It was previously found that the chemical composition of anal scent gland secretions as well as urine is significantly different in male and female ferrets (in breeding condition) (Zhang et al., 2005). Exposure to volatile components of anal scent gland secretions stimulated distinguishable patterns of glomerular activation (again, indexed using Fos expression in periglomerular neurons) in both male and female ferrets that were in breeding condition (no sex differences were seen at the level of the MOB) (Woodley and Baum, 2004). In ferrets, as in several of the above-mentioned species, a reliable sex difference was observed in the preference to investigate pheromonal cues from conspecifics, and these sexually dimorphic preferences were only expressed when gonadal steroids were circulating at the time that odor preferences were assessed. In one study (Chang et al., 2000) sexually experienced adult male and female ferrets were gonadectomized and tested for their preference to investigate (sniff) blocks of wood previously soiled with anal scent gland secretions/urine from breeding male vs. female ferrets.

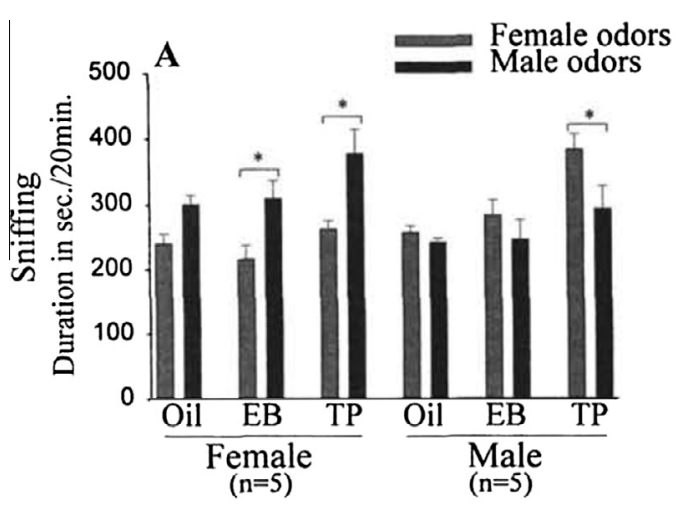

Fig. 10. Investigation (sniffing duration) directed by male vs. female ferrets towards wood blocks previously soiled with body odors from breeding male vs. female ferrets. Prior to collecting these data, ferrets were gonadectomized as adults, injected daily with testosterone propionate (TP) for 2 weeks, and allowed to have physical contact with a breeding male followed several days later by an estrous female in order to provide olfactory experience with male and female scents. Subjects were then tested at 4-week intervals while receiving daily s.c. injections of (in sequence) TP, sesame oil vehicle, and estradiol benzoate (EB). A significant preference to investigate opposite-sex pheromones was seen in gonadectomized females and males, provided an 'activational' sex hormone (TP or EB) was being administered. Data are expressed as mean \pm SEM and group size is given in parentheses. ${ }^{*} p<0.05$ comparisons showing significant odor preferences in ferrets of each sex. Adapted with permission from Chang et al. (2000).

No significant preference for male vs. female odors was seen in either sex when they received only the oil vehicle that was later used to deliver sex steroids subcutaneously (Fig. 10). By contrast, when gonadectomized subjects were given EB injections continuously for 2 weeks, females showed a significant preference to investigate male over female pheromones whereas males showed no preference for either type of odor. Finally, when given TP for 2 weeks, female subjects continued to prefer to investigate male vs. female odors whereas male subjects showed a significant preference to investigate female vs. male odors (Fig. 10). Additional research showed that bilateral nares occlusion, which blocked all access of volatile odorants to the MOE, completely eliminated the preference of male as well as female ferrets to approach opposite-sex subjects, even when a physical interaction was allowed with those stimulus ferrets (Kelliher and Baum, 2001). Surgical VNO removal failed to block the preference of female ferrets to approach male vs. female pheromones in Y maze tests (Woodley et al., 2004)-providing further evidence that the main olfactory system, alone, is capable of mediating the preference of ferrets for opposite-sex pheromones. Two early studies (Kelliher et al., 1998; Wersinger and Baum, 1997) used Fos expression to reveal the existence of sexually dimorphic profiles of neuronal activation in the olfactory projection circuit from the medial amygdala (which receives inputs from both the main and accessory olfactory systems) to targets in the ferret's hypothalamus, including the BNST, MPOA, and VMH. Two additional studies examined the effects of lesioning different hypothalamic regions on the preference of female and male ferrets to seek out same- vs. opposite-sex pheromones in operant tests. Thus, bilateral lesions of the VMH (but not of the $\mathrm{MPOA}$ ) in female ferrets blocked their preference to seek out male vs. female volatile pheromones, without disrupting subjects' ability to discriminate between these same odors when they were presented sequentially in habituation/dishabituation tests (Robarts and Baum, 2007). By contrast, bilateral lesions of the sexually dimorphic male nucleus of the POA/AH (Kindon et al., 1996; Paredes and Baum, 1995) actually reversed the normal heterosexual odor preference of male ferrets so that after receiving this lesion they preferred to approach volatile odors from other males (homosexual preference). This switch in odor preference following POA/ $\mathrm{AH}$ lesions implies that in the absence of this male-specific cluster 
of neurons in the POA/AH, male subjects would display the default, female-typical preference to seek out male odors. This hypothesis was confirmed in a study (Alekseyenko et al., 2007) showing that bilateral lesions of the male nucleus of the POA/AH in male ferrets caused them to prefer to approach volatile body odors from other male ferrets. These lesioned ferrets also showed a female-like profile of rostral medial POA Fos responses to volatile male odors. There is some disagreement about whether lesions of the POA/ AH feminizes partner preference in males of other species. Thus in rats, Paredes et al. (1998) reported such a switch in preference following lesioning of the male's POA (including but not restricted to the SDN) whereas more recently another study (Dhungel et al., 2011) reported that lesions placed in this region eliminated males' typical female-oriented preference without causing a preference reversal.

It is interesting to note that male sheep possess a sexually dimorphic cluster of neurons in the mPOA/AH (ovine sexually dimorphic nucleus; oSDN) which appears to be homologous to the nucleus described in several other mammals, including rat, guinea pig, ferret, rhesus monkey, and man. Size of the ovine SDN in male sheep is correlated with subjects' sexual orientation: males with the largest oSDN prefer to seek out and mount an estrous female whereas other males, with significantly smaller oSDNs, showed a spontaneous preference to mount other males instead of females (Roselli et al., 2004a, 2004b). It is interesting to note that Fos immunoreactivity in the $\mathrm{MPOA} / \mathrm{AH}$ was significantly higher in female-oriented than in male-oriented rams that were exposed to the sight, sound and smell of either ewes or other rams (Alexander et al., 2001; Roselli et al., 2011). In future studies it will be important to determine whether experimental destruction of the oSDN in proven, heterosexual rams will cause a reversal of their preferred mating partner to another male, and whether any such change correlates specifically with hypothalamic Fos responses to male vs. female sheep pheromones. It is noteworthy that in humans the volume of the sexually dimorphic third interstitial nucleus of the anterior hypothalamus (INAH3) is also correlated with sexual orientation (Byne et al., 2001; LeVay, 1991). The volume of the INAH3 was significantly smaller in gay than in straight men. The extent to which the function of the INAH3 (humans) in sexual orientation reflects differential processing of pheromonal cues (e.g., AND) is not known.

\subsection{Role of sex chromosome genes in odor preferences}

As mentioned already, numerous experiments (Bakker et al., 1993; Baum et al., 1990; de Jonge et al., 1988; Johnson and Tiefer, 1972; Meyerson et al., 1978) have explored the contribution of organizational actions of testosterone and/or of estradiol to the differentiation of circuits that control sex partner preference and mate recognition in the male. An alternative explanation of hardwired sex differences in brain circuits that control social behavior, including the processing of pheromones, involves direct neural actions of genes expressed off either the $\mathrm{X}$ and/or $\mathrm{Y}$ chromosome during development (McCarthy and Arnold, 2011). A model system to address this issue is the 'four core cross' murine model of sexual differentiation in which the manipulation of the expression of the testes formation gene, Sry, leads to the generation of mice with testes ('males') that are either XX or XY as well as the generation of mice with ovaries ('females') that are either XX or XY. An early study (Gatewood et al., 2006) provided evidence that developmental actions of gonadal hormones (presumably testosterone secreted in males by the testes), as opposed to genes expressed of the sex chromosomes, are responsible for the strong preference of male mice to seek out pheromones from an estrous female vs. a testes-intact male, with the reverse preference being seen in female mice. Future studies are needed to replicate and extend this work to other aspects of pheromone detection and processing. For example, Rissman and co-workers (Bonthuis et al., 2012) reported that the dosage of yet-to-be-specified gene(s) expressed of the X chromosome significantly affect mating performance in male mice. More research is needed to determine whether this behavioral effect is mediated by a modulation of the structure and function of circuits that detect and process female pheromones, perhaps in response to X chromosome genes. Specifying specific roles for particular X chromosome genes will also be required.

\subsection{Feminizing role of estradiol in odor preferences}

We recently asked whether estradiol makes an active contribution to the feminization of neural circuits that control olfactory mate recognition in the female mouse. The data obtained (Brock et al., 2011, 2010a) contradict the widely held view that the nervous system of female mammals develops (in contrast to the male) without any active 'organizational' contribution of sex hormones. Indeed, one of us (Bakker et al., 2006) showed that during fetal development female mice must be actively protected from the potential defeminizing/masculinizing actions of any estradiol that might otherwise reach the gestating female fetus from either maternal sources or from adjacent males in utero. This protection is accomplished by hepatic secretion of alpha feto protein (AFP). Knocking out the AFP gene caused a dramatic defeminization of mating behavior capacity in female mice; this effect was rescued by preventing the fetal formation of estradiol by treating these AFP KO females with an aromatase blocking drug, ATD. Given these results, it was surprising to note (Bakker et al., 2002) that the capacity of female mice to display lordosis behavior in response to adult ovarian hormones and display a reliable, female-typical preference to approach male pheromones was absent in ArKO females, which lack the capacity to synthesize estradiol in any body tissues. As shown in Fig. 11, when adult WT female mice (WT control) were ovariectomized in adulthood and treated with ovarian hormones they showed a significant preference to approach a

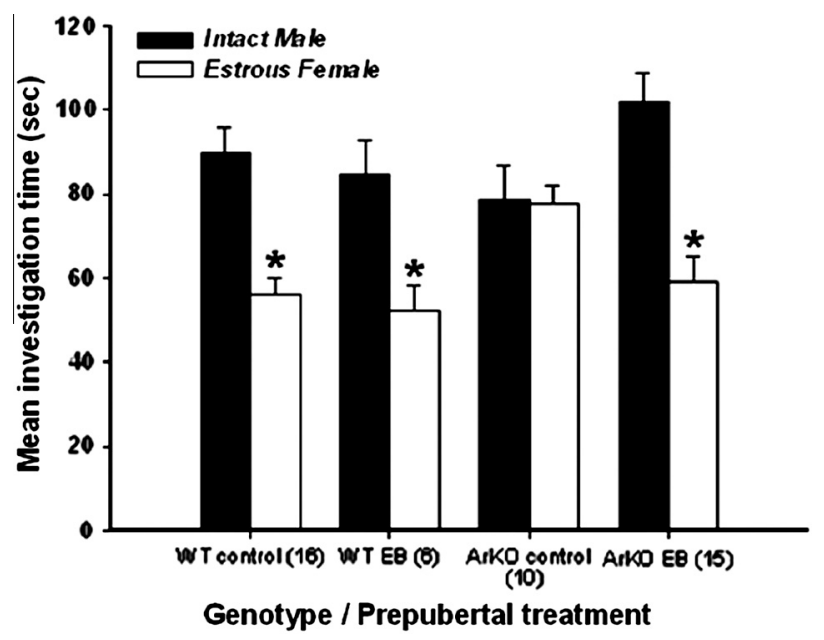

Fig. 11. Wild type female mice that were primed with estradiol followed by progesterone only at the time of adult testing (WT control) preferred to investigate volatile pheromones from a testes-intact male vs. an estrous female. No such preference was seen in aromatase knockout females (ArKO control) that were also primed in adulthood with ovarian hormones. Prepubertal injections of estradiol benzoate (EB) over postnatal days 15-25 reinstated the preference of ArKO females (ArKO EB) to prefer investigating male odors. Prepubertal administration of EB to WT females did not affect their later preference for male odors. Data are expressed as mean \pm SEM and group sizes are given in parentheses. $" p<0.05$ within group comparisons of investigation times toward odors from a testes-intact male vs. an estrous female. Adapated with permission from Brock et al. (2011). 
compartment that emitted volatile body odors from a testes-intact male vs. an estrous female mouse (Brock et al., 2011). Administering EB daily across postnatal days 15-25 (WT EB) failed to influence the later, adult preference profile of WT females. ArKO females that received no prepubertal (P15-P25) hormones (ArKO Control) showed no preference to approach volatile odors from an intact male vs. an estrous female following adult ovariectomy and treatment with ovarian hormones. Importantly, the normal male-oriented odor preference of WT females was 'rescued' in ArKO females that were given EB over the prepubertal period (P15-P25), prior to being tested several weeks later while receiving ovarian hormones. This rescue of the capacity to display a femaletypical pheromone preference after prepubertal estradiol treatment was paralleled by a rescue of the capacity to display lordosis behavior in response to the receipt of male mounts in these same ArKO females (Brock et al., 2011). In both instances further research is needed to specify the morphological changes in the developing olfactory circuits that are induced by prepubertal estradiol which lead to the female-typical pheromone detection and processing in adulthood.

\section{Future directions}

The possible role of sex steroids as pheromonal signaling molecules remains a matter of speculation based on a minimal amount of hard data. Surprisingly perhaps, to date the best-documented (though still controversial) example of a sex steroid that fulfills at least some of the criteria for being called a 'pheromone' is androstadienone, a component of underarm sweat in men. There is wide agreement that this steroid is detected by the main olfactory system in both men and women whereupon it activates a neural circuit that includes regions of the hypothalamus. More work is needed, using improved brain imaging methods with better resolution than fMRI or PET, to see whether the hypothalamic regions responding to androstadienone in humans correspond to those regions that respond to urinary and/or tear pheromones in mice, rats, hamsters, and ferrets. In these latter species, which all possess a functional VNO-accessory olfactory system, more research is also needed to determine whether sulfated sex steroids, known to be potent activators of VNO sensory neurons, at least in mice, exert any specific behavioral or neuroendocrine actions in this species. More research is also needed to determine whether sulfated steroids activate central segments (medial amygdala, BNST, mPOA, etc.) of the olfactory projection pathway.

Numerous studies, already reviewed, suggest that sex hormones exert activational effects on both the initial detection and the subsequent central processing of pheromones detected by either the main or the accessory systems in several mammalian model systems. Whereas estradiol receptors (both alpha and beta subtypes) and/or androgen receptors are expressed at several central levels of the putative pheromone processing circuit (e.g., MOB, medial amgydala, BNST, anterior olfactory nucleus, mPOA, and piriform cortex) (Kelliher et al., 1998; Shughrue et al., 1997), there is no evidence of steroid receptor expression in either the VNO or MOE sensory epithelium. Future studies will determine whether testosterone and/or estradiol act selectively along this olfactory pathway to modulate pheromone processing. For example, estradiol formed via the neural metabolism of testosterone in adult male rats apparently acts mainly in the MPOA to facilitate the expression of mating (Paisley et al., 2012; Russell et al., 2012), perhaps due to enhanced processing of pheromonal inputs from estrous females in this critical brain region. Both the main and accessory bulbs receive significant centrifugal inputs comprised of noradrenergic neurons located in the locus coeruleus, which also express androgen and estradiol receptors (Heritage et al., 1980;
Shughrue et al., 1997). Two early studies (Shang and Dluzen, $1998,2001)$ raised the possibility that the testosterone-induced enhancement of the responses of male rats to estrous female pheromones depends on the upregulation of noradrenergic signaling in the MOB. More work is needed to follow up on this possibility while extending the analysis to possible steroidal modulation of cholinergic and/or serotoninergic inputs to the MOB. Other studies (Larsen and Grattan, 2010; Larsen et al., 2008) showed that chronic exposure to male pheromones over approximately 3 weeks (the duration of pregnancy) advanced the onset of maternal responsiveness in both virgin and pregnant female mice. This behavioral action of male pheromones was linked to the birth of new neurons in the ventricular zone followed by their migration along the rostral migratory stream into the MOB. Both the morphological and parenting behavior responses to male pheromones were blocked in females that were ovariectomized or in which prolactin secretion was pharmacologically suppressed for a few days after the onset of male pheromone exposure. Ovarian steroids, together with prolactin, appear to facilitate maternal responsiveness in female mice by stimulating structural changes in the ability of the main olfactory system to process pheromonal cues. Other recent evidence (Tachikawa et al., 2013) raises the possibility that prolonged exposure of male mice to pheromonal cues from a pregnant female enhances olfactory learning in the accessory olfactory system so as to make males display robust parental behavior towards pups, once they are born. Surgical VNO removal in naïve (non-father) males caused them to display a rapid onset of female-like parental behavior towards pups, implicating the accessory olfactory system in this process. Future studies should explore the possible effects of sex steroids in brain regions that extend centrifugal inputs to both the main and accessory olfactory peripheral receptors as well as the respective olfactory bulbs of each system.

\section{Acknowledgments}

Dr. Bakker is a Senior Research Associate of the Belgian FNRS. Her contribution to preparing this review was supported by grants from the Belgian Fonds de la Recherche Scientifique Medicale (FRSM), Belgium, No. 3.4571.10, and from the Nederlandse Organisatie voor Wetenschappelijk Onderzoek (NWO-VICI 453-08-003).

\section{References}

Alekseyenko, O.V., Baum, M.J., Cherry, J.A., 2006. Sex and gonadal steroid modulation of pheromone receptor gene expression in the mouse vomeronasal organ. Neuroscience 140, 1349-1357.

Alekseyenko, O.V., Waters, P., Zhou, H., Baum, M.J., 2007. Bilateral damage to the sexually dimorphic medial preoptic area/anterior hypothalamus of male ferrets causes a female-typical preference for and a hypothalamic Fos response to male body odors. Physiol. Behav. 90, 438-449.

Alexander, B.M., Rose, J.D., Stellflug, J.N., Fitzgerald, J.A., Moss, G.E., 2001. Fos-like immunoreactivity in brain regions of domestic rams following exposure to rams or ewes. Physiol. Behav. 73, 75-80.

Bakker, J., Baum, M.J., Slob, A.K., 1996. Neonatal inhibition of brain estrogen synthesis alters adult neural Fos responses to mating and pheromonal stimulation in the male rat. Neuroscience 74, 251-260.

Bakker, J., Brand, T., van Ophemert, J., Slob, A.K., 1993. Hormonal regulation of adult partner preference behavior in neonatally ATD-treated male rats. Behav. Neurosci. 107, 480-487.

Bakker, J., De Mees, C., Douhard, Q, Balthazart, J., Gabant, P., Szpirer, J., Szpirer, C. 2006. Alpha-fetoprotein protects the developing female mouse brain from masculinization and defeminization by estrogens. Nat. Neurosci. 9, 220-226.

Bakker, J., Honda, S., Harada, N., Balthazart, J., 2002. The aromatase knock-out mouse provides new evidence that estradiol is required during development in the female for the expression of sociosexual behaviors in adulthood. J. Neurosci. 22, 9104-9112.

Baum, M.J. 1979. Differentiation of coital behavior in mammals: a comparative analysis. Neurosci. Biobehav. Rev. 3, 265-284.

Baum, M.J., 2009. Sexual differentiation of pheromone processing: links to maletypical mating behavior and partner preference. Horm. Behav. 55, 579-588.

Baum, M.J., Erskine, M.S., Kornberg, E., Weaver, C.E., 1990. Prenatal and neonatal testosterone exposure interact to affect differentiation of sexual behavior and partner preference in female ferrets. Behav. Neurosci. 104, 183-198. 
Baum, M.J., Everitt, B.J., 1992. Increased expression of c-fos in the medial preoptic area after mating in male rats: role of afferent inputs from the medial amygdala and midbrain central tegmental field. Neuroscience 50, 627-646.

Baum, M.J., Keverne, E.B., 2002. Sex difference in attraction thresholds for volatile odors from male and estrous female mouse urine. Horm. Behav. 41, 213219.

Baum, M.J., Sodersten, P., Vreeburg, J.T., 1974. Mounting and receptive behavior in the ovariectomized female rat: influence of estradiol, dihydrotestosterone, and genital anesthetization. Horm. Behav. 5, 175-190.

Ben-Shaul, Y., Katz, L.C., Mooney, R., Dulac, C., 2010. In vivo vomeronasal stimulation reveals sensory encoding of conspecific and allospecific cues by the mouse accessory olfactory bulb. Proc. Natl. Acad. Sci. USA 107, 5172-5177.

Berglund, H., Lindstrom, P., Dhejne-Helmy, C., Savic, I., 2008. Male-to-female transsexuals show sex-atypical hypothalamus activation when smelling odorous steroids. Cereb. Cortex 18, 1900-1908.

Berglund, H., Lindstrom, P., Savic, I., 2006. Brain response to putative pheromones in lesbian women. Proc. Natl. Acad. Sci. USA 103, 8269-8274.

Bodo, C., Rissman, E.F., 2007. Androgen receptor is essential for sexual differentiation of responses to olfactory cues in mice. Eur. J. Neurosci. 25, 2182-2190.

Bonthuis, P.J., Cox, K.H., Rissman, E.F., 2012. X-chromosome dosage affects male sexual behavior. Horm. Behav. 61, 565-572.

Brennan, P.A., 2004. The nose knows who's who: chemosensory individuality and mate recognition in mice. Horm. Behav. 46, 231-240.

Brennan, P.A., Zufall, F., 2006. Pheromonal communication in vertebrates. Nature $444,308-315$.

Bressler, S.C., Baum, M.J., 1996. Sex comparison of neuronal Fos immunoreactivity in the rat vomeronasal projection circuit after chemosensory stimulation. Neuroscience 71, 1063-1072.

Brock, O., Baum, M.J., Bakker, J., 2011. The development of female sexual behavior requires prepubertal estradiol. J. Neurosci. 31, 5574-5578.

Brock, O., Douhard, Q., Baum, M.J., Bakker, J., 2010a. Reduced prepubertal expression of progesterone receptor in the hypothalamus of female aromatase knockout mice. Endocrinology 151, 1814-1821.

Brock, O., Keller, M., Veyrac, A., Douhard, Q., Bakker, J., 2010b. Short term treatment with estradiol decreases the rate of newly generated cells in the subventricular zone and main olfactory bulb of adult female mice. Neuroscience 166, 368-376.

Brouette-Lahlou, I., Vernet-Maury, E., Chanel, J., 1991. Is rat-dam licking behavior regulated by pups' preputial gland secretion? Anim. Learn. Behav. 19, 177-184.

Brown, R.E., 1977. Odor preference and urine-marking scales in male and female rats: effects of gonadectomy and sexual experience on conspecific odors. J. Comp. Physiol. Psychol., 9.

Bruce, H.M., 1959. An exteroceptive block to pregnancy in the mouse. Nature 184, 105.

Buck, L., Axel, R., 1991. A novel multigene family may encode odorant receptors: a molecular basis for odor recognition. Cell 65, 175-187.

Burke, S.M., Veltman, D.J., Gerber, J., Hummel, T., Bakker, J., 2012. Heterosexual men and women both show a hypothalamic response to the chemo-signal androstadienone. PLoS ONE 7, e40993.

Byne, W., Tobet, S., Mattiace, L.A., Lasco, M.S., Kemether, E., Edgar, M.A., Morgello, S. Buchsbaum, M.S., Jones, L.B., 2001. The interstitial nuclei of the human anterior hypothalamus: an investigation of variation with sex, sexual orientation, and HIV status. Horm. Behav. 40, 86-92.

Carr, W.J., Loeb, L.S., Wylie, N.R., 1966. Responses to feminine odors in normal and castrated male rats. J. Comp. Physiol. Psychol. 62, 336-338.

Celsi, F., D’Errico, A., Menini, A., 2012. Responses to sulfated steroids of female mouse vomeronasal sensory neurons. Chem. Senses 37, 849-858.

Chamero, P., Leinders-Zufall, T., Zufall, F., 2012. From genes to social communication: molecular sensing by the vomeronasal organ. Trends Neurosci. 35, 597-606.

Chang, Y.M., Kelliher, K.R., Baum, M.J., 2000. Steroidal modulation of scent investigation and marking behaviors in male and female ferrets. J. Comp. Psychol. 114, 401-407.

Chopra, A., Baur, A., Hummel, T., 2008. Thresholds and chemosensory event-related potentials to malodors before, during, and after puberty: differences related to sex and age. Neuroimage 40, 1257-1263.

Ciumas, C., Linden Hirschberg, A., Savic, I., 2009. High fetal testosterone and sexually dimorphic cerebral networks in females. Cereb. Cortex 19, 1167-1174.

de Jonge, F.H., Muntjewerff, J.W., Louwerse, A.L., van de Poll, N.E., 1988. Sexual behavior and sexual orientation of the female rat after hormonal treatment during various stages of development. Horm. Behav. 22, 100-115.

deCatanzaro, D., Beaton, E.A., Khan, A., Vella, E., 2006. Urinary oestradiol and testosterone levels from novel male mice approach values sufficient to disrupt early pregnancy in nearby inseminated females. Reproduction 132, 309-317.

Dhungel, S., Urakawa, S., Kondo, Y., Sakuma, Y., 2011. Olfactory preference in the male rat depends on multiple chemosensory inputs converging on the preoptic area. Horm. Behav. 59, 193-199.

Dorries, K.M., Adkins-Regan, E., Halpern, B.P., 1995. Olfactory sensitivity to the pheromone, androstenone, is sexually dimorphic in the pig. Physiol. Behav. 57, 255-259.

Dorries, K.M., Adkins-Regan, E., Halpern, B.P., 1997. Sensitivity and behavioral responses to the pheromone androstenone are not mediated by the vomeronasal organ in domestic pigs. Brain Behav. Evol. 49, 53-62.

Dorries, K.M., Schmidt, H.J., Beauchamp, G.K., Wysocki, C.J., 1989. Changes in sensitivity to the odor of androstenone during adolescence. Dev. Psychobiol. 22, 423-435.
Doty, R.L., Ferguson-Segall, M., 1989. Influence of adult castration on the olfactory sensitivity of the male rat: a signal detection analysis. Behav. Neurosci. 103, 691-694.

Dulac, C., Axel, R., 1995. A novel family of genes encoding putative pheromone receptors in mammals. Cell 83, 195-206.

Edwards, D.A., 1971. Early androgen treatment and male and female sexual behavior in mice. Horm. Behav. 2, 49-58.

Emery, D.E., Sachs, B.D., 1975. Ejaculatory pattern in female rats without androgen treatment. Science 190, 484-486.

Ferkin, M.H., 1992. Time course of androgenic modulation of odor preferences and odor cues in male meadow voles, Microtus pennsylvanicus. Horm Behav. 26 $512-521$

Fiber, J.M., Swann, J.M., 1996. Testosterone differentially influences sex-specific pheromone-stimulated Fos expression in limbic regions of Syrian hamsters Horm. Behav. 30, 455-473.

Frasnelli, J., Lundstrom, J.N., Boyle, J.A., Katsarkas, A., Jones-Gotman, M., 2011. The vomeronasal organ is not involved in the perception of endogenous odors. Hum. Brain Mapp. 32, 450-460.

Gatewood, J.D., Wills, A., Shetty, S., Xu, J., Arnold, A.P., Burgoyne, P.S., Rissman, E.F. 2006. Sex chromosome complement and gonadal sex influence aggressive and parental behaviors in mice. J. Neurosci. 26, 2335-2342.

Guillamon, A., Segovia, S., 1997. Sex differences in the vomeronasal system. Brain Res. Bull, 44, 377-382.

Guzzo, A.C., Berger, R.G., deCatanzaro, D., 2010. Excretion and binding of tritiumlabelled oestradiol in mice (Mus musculus): implications for the Bruce effect Reproduction 139, 255-263.

Guzzo, A.C., Jheon, J., Imtiaz, F., deCatanzaro, D., 2012. Oestradiol transmission from males to females in the context of the Bruce and Vandenbergh effects in mice (Mus musculus). Reproduction 143, 539-548.

Halem, H.A., Baum, M.J., Cherry, J.A., 2001a. Sex difference and steroid modulation of pheromone-induced immediate early genes in the two zones of the mouse accessory olfactory system. J. Neurosci. 21, 2474-2480.

Halem, H.A., Cherry, J.A., Baum, M.J., 1999. Vomeronasal neuroepithelium and forebrain Fos responses to male pheromones in male and female mice. J. Neurobiol. 39, 249-263.

Halem, H.A., Cherry, J.A., Baum, M.J., 2001b. Central forebrain Fos responses to familiar male odours are attenuated in recently mated female mice. Eur. J. Neurosci. 13, 389-399.

He, J., Ma, L., Kim, S., Nakai, J., Yu, C.R., 2008. Encoding gender and individual information in the mouse vomeronasal organ. Science 320, 535-538.

He, J., Ma, L., Kim, S., Schwartz, J., Santilli, M., Wood, C., Durnin, M.H., Yu, C.R., 2010 Distinct signals conveyed by pheromone concentrations to the mouse vomeronasal organ. J. Neurosci. 30, 7473-7483.

Heritage, A.S., Stumpf, W.E., Sar, M., Grant, L.D., 1980. Brainstem catecholamine neurons are target sites for sex steroid hormones. Science 207, 1377-1379.

Herrada, G., Dulac, C., 1997. A novel family of putative pheromone receptors in mammals with a topographically organized and sexually dimorphic distribution. Cell 90, 763-773.

Holy, T.E., Dulac, C., Meister, M., 2000. Responses of vomeronasal neurons to natura stimuli. Science 289, 1569-1572.

Isogai, Y., Si, S., Pont-Lezica, L., Tan, T., Kapoor, V., Murthy, V.N., Dulac, C., 2011. Molecular organization of vomeronasal chemoreception. Nature 478, 241 245.

Jacob, S., Garcia, S., Hayreh, D., McClintock, M.K., 2002. Psychological effects of musky compounds: comparison of androstadienone with androstenol and muscone. Horm. Behav. 42, 274-283.

Jacob, S., McClintock, M.K., 2000. Psychological state and mood effects of steroida chemosignals in women and men. Horm. Behav, 37, 57-78.

Johnson, W.A., Tiefer, L., 1972. Sexual preferences in neonatally castrated male golden hamsters. Physiol. Behav. 9, 213-217.

Kang, N., Baum, M.J., Cherry, J.A., 2009. A direct main olfactory bulb projection to the 'vomeronasal' amygdala in female mice selectively responds to volatile pheromones from males. Eur. J. Neurosci. 29, 624-634.

Kang, N., Baum, M.J., Cherry, J.A., 2011a. Different profiles of main and accessory olfactory bulb mitral/tufted cell projections revealed in mice using an anterograde tracer and a whole-mount, flattened cortex preparation. Chem. Senses 36, 251-260.

Kang, N., McCarthy, E.A., Cherry, J.A., Baum, M.J. 2011b. A sex comparison of the anatomy and function of the main olfactory bulb-medial amygdala projection in mice. Neuroscience 172, 196-204.

Karlson, P., Luscher, M., 1959. Pheromones': a new term for a class of biologically active substances. Nature 183, 55-56.

Keller, A., Zhuang, H., Chi, Q., Vosshall, L.B., Matsunami, H., 2007. Genetic variation in a human odorant receptor alters odour perception. Nature 449, 468-472.

Kelliher, K.R., Baum, M.J., 2001. Nares occlusion eliminates heterosexual partne selection without disrupting coitus in ferrets of both sexes. J. Neurosci. 21, $5832-5840$

Kelliher, K.R., Chang, Y.M., Wersinger, S.R., Baum, M.J., 1998. Sex difference and testosterone modulation of pheromone-induced NeuronalFos in the Ferret's main olfactory bulb and hypothalamus. Biol. Reprod. 59, 1454-1463.

Kevetter, G.A., Winans, S.S., 1981a. Connections of the corticomedial amygdala in the golden hamster. I. Efferents of the "vomeronasal amygdala". J. Comp. Neurol. 197, 81-98.

Kevetter, G.A., Winans, S.S., 1981b. Connections of the corticomedial amygdala in the golden hamster. II. Efferents of the "olfactory amygdala". J. Comp. Neurol 197, 99-111. 
Kimchi, T., Xu, J., Dulac, C., 2007. A functional circuit underlying male sexual behaviour in the female mouse brain. Nature 448, 1009-1014.

Kindon, H.A., Baum, M.J., Paredes, R.J., 1996. Medial preoptic/anterior hypothalamic lesions induce a female-typical profile of sexual partner preference in male ferrets. Horm. Behav. 30, 514-527.

Kollack, S.S., Newman, S.W., 1992. Mating behavior induces selective expression of Fos protein within the chemosensory pathways of the male Syrian hamster brain. Neurosci. Lett. 143, 223-228.

Kovacs, G., Gulyas, B., Savic, I., Perrett, D.I., Cornwell, R.E., Little, A.C., Jones, B.C., Burt, D.M., Gal, V., Vidnyanszky, Z., 2004. Smelling human sex hormone-like compounds affects face gender judgment of men. NeuroReport 15, 1275-1277.

Larriva-Sahd, J., 2008. The accessory olfactory bulb in the adult rat: a cytologica study of its cell types, neuropil, neuronal modules, and interactions with the main olfactory system. J. Comp. Neurol. 510, 309-350.

Larsen, C.M., Grattan, D.R., 2010. Prolactin-induced mitogenesis in the subventricular zone of the maternal brain during early pregnancy is essential for normal postpartum behavioral responses in the mother. Endocrinology 151, 3805-3814.

Larsen, C.M., Kokay, I.C., Grattan, D.R., 2008. Male pheromones initiate prolactininduced neurogenesis and advance maternal behavior in female mice. Horm. Behav. 53, 509-517.

Leinders-Zufall, T., Brennan, P., Widmayer, P., S, P.C., Maul-Pavicic, A., Jager, M., Li, X.H., Breer, H., Zufall, F., Boehm, T., 2004. MHC class I peptides as chemosensory signals in the vomeronasal organ. Science 306, 1033-1037.

Leinders-Zufall, T., Lane, A.P., Puche, A.C., Ma, W., Novotny, M.V., Shipley, M.T. Zufall, F., 2000. Ultrasensitive pheromone detection by mammalian vomeronasal neurons. Nature 405, 792-796.

LeVay, S., 1991. A difference in hypothalamic structure between heterosexual and homosexual men. Science 253, 1034-1037.

Lloyd-Thomas, A., Keverne, E.B., 1982. Role of the brain and accessory olfactory system in the block to pregnancy in mice. Neuroscience 7, 907-913.

Lundstrom, J.N., Hummel, T., Olsson, M.J., 2003. Individual differences in sensitivity to the odor of 4,16-androstadien-3-one. Chem. Senses 28, 643-650.

Luo, M., Fee, M.S., Katz, L.C., 2003. Encoding pheromonal signals in the accessory olfactory bulb of behaving mice. Science 299, 1196-1201.

Martel, K.L., Baum, M.J., 2007. Sexually dimorphic activation of the accessory, but not the main, olfactory bulb in mice by urinary volatiles. Eur. J. Neurosci. 26 463-475

Martel, K.L., Baum, M.J., 2009a. Adult testosterone treatment but not surgical disruption of vomeronasal function augments male-typical sexual behavior in female mice. J. Neurosci. 29, 7658-7666.

Martel, K.L., Baum, M.J., 2009b. A centrifugal pathway to the mouse accessory olfactory bulb from the medial amygdala conveys gender-specific volatile pheromonal signals. Eur. J. Neurosci. 29, 368-376.

Martins, Y., Preti, G., Crabtree, C.R., Runyan, T., Vainius, A.A., Wysocki, C.J., 2005. Preference for human body odors is influenced by gender and sexual orientation. Psychol. Sci. 16, 694-701.

Matsunami, H., Buck, L.B., 1997. A multigene family encoding a diverse array of putative pheromone receptors in mammals. Cell 90, 775-784.

McCarthy, M.M., Arnold, A.P., 2011. Reframing sexual differentiation of the brain Nat. Neurosci. 14, 677-683.

McClintock, M.K., 2002. Pheromones, odors, and vasanas: the neuroendocrinology of social chemosignals in humans and animals. In: Pfaff et al. (Eds.), Hormones, Brain and Behavior. Elsevier, San Diego, pp. 797-870.

Meeks, J.P., Arnson, H.A., Holy, T.E., 2010. Representation and transformation of sensory information in the mouse accessory olfactory system. Nat. Neurosci. 13 723-730.

Meredith, M., 2001. Human vomeronasal organ function: a critical review of best and worst cases. Chem. Senses 26, 433-445.

Meredith, M., O'Connell, R.J., 1979. Efferent control of stimulus access to the hamster vomeronasal organ. J. Physiol. 286, 301-316.

Meyerson, B.J., Eliasson, M., Hetta, J., 1978. Sex-specific orientation in female and male rats: development and effects of early endocrine manipulations. Adv. Biosci. 25, 451-460.

Moore, C.L., Samonte, B.R., 1986. Preputial glands of infant rats provide chemosignals for maternal discrimination of sex. J. Comp. Psychol. 100, 76-80.

Nakajima, D., Nakayama, M., Kikuno, R., Hirosawa, M., Nagase, T., Ohara, O., 2001 Identification of three novel non-classical cadherin genes throug comprehensive analysis of large cDNAs. Brain Res. Mol. Brain Res. 94, 85-95.

Nodari, F., Hsu, F.F., Fu, X., Holekamp, T.F., Kao, L.F., Turk, J., Holy, T.E., 2008. Sulfated steroids as natural ligands of mouse pheromone-sensing neurons. J. Neurosci. 28, 6407-6418.

Novotny, M.V., 2003. Pheromones, binding proteins and receptor responses in rodents. Biochem. Soc. Trans. 31, 117-122.

Nyby, J., Wysocki, C.J., Whitney, G., Dizinno, G., 1977. Pheromonal regulation of male mouse ultrasonic courtship (Mus musculus). Anim. Behav. 25, 333-341.

Paisley, J.C., Huddleston, G.G., Carruth, L.L., Petrulis, A., Grober, M.S., Clancy, A.N. 2012. Sexual responses of the male rat medial preoptic area and medial amygdala to estrogen I: site specific suppression of estrogen receptor alpha. Horm. Behav. 62, 50-57.

Pankevich, D.E., Deedy, E.M., Cherry, J.A., Baum, M.J., 2003. Interactive effects of testosterone and superior cervical ganglionectomy on attraction thresholds to volatile urinary odors in gonadectomized mice. Behav. Brain Res. 144, 157-165.

Paredes, R.G., Baum, M.J., 1995. Altered sexual partner preference in male ferrets given excitotoxic lesions of the preoptic area/anterior hypothalamus. Neurosci. 15, 6619-6630.
Paredes, R.G., Tzschentke, T., Nakach, N., 1998. Lesions of the medial preoptic area/ anterior hypothalamus (MPOA/AH) modify partner preference in male rats. Brain Res. 813, 1-8

Parma, V., Tirindelli, R., Bisazza, A., Massaccesi, S., Castiello, U., 2012. Subliminally perceived odours modulate female intrasexual competition: an eye movement study. PLoS ONE 7, e30645.

Petrulis, A., 2013. Chemosignals, hormones, and mammlian reproduction. Horm. Behav. 63, 723-741.

Pfaff, D.W., Gregory, E., 1971. Olfactory coding in olfactory bulb and medial forebrain bundle of normal and castrated male rats. J. Neurophysiol. 34, 208216.

Pfaff, D.W., Pfaffmann, C., 1969. Olfactory and hormonal influences on the basal forebrain of the male rat. Brain Res. 15, 137-156.

Pierman, S., Douhard, Q., Bakker, J., 2008. Evidence for a role of early oestrogens in the central processing of sexually relevant olfactory cues in female mice. Eur. J. Neurosci. 27, 423-431.

Pierman, S., Douhard, Q., Balthazart, J., Baum, M.J., Bakker, J., 2006. Attraction thresholds and sex discrimination of urinary odorants in male and female aromatase knockout (ArKO) mice. Horm. Behav. 49, 96-104.

Pro-Sistiaga, P., Mohedano-Moriano, A., Ubeda-Banon, I., Del Mar Arroyo-Jimenez, M., Marcos, P., Artacho-Perula, E., Crespo, C., Insausti, R., Martinez-Marcos, A., 2007. Convergence of olfactory and vomeronasal projections in the rat basal telencephalon. J. Comp. Neurol. 504, 346-362.

Robarts, D.W., Baum, M.J., 2007. Ventromedial hypothalamic nucleus lesions disrupt olfactory mate recognition and receptivity in female ferrets. Horm. Behav. 51, 104-113.

Robertson, G.S., Pfaus, J.G., Atkinson, L.J., Matsumura, H., Phillips, A.G., Fibiger, H.C., 1991. Sexual behavior increases c-fos expression in the forebrain of the male rat. Brain Res. 564, 352-357.

Roselli, C.E., Larkin, K., Resko, J.A., Stellflug, J.N., Stormshak, F., 2004a. The volume of a sexually dimorphic nucleus in the ovine medial preoptic area/anterior hypothalamus varies with sexual partner preference. Endocrinology 145, 478-483.

Roselli, C.E., Larkin, K., Schrunk, J.M., Stormshak, F., 2004b. Sexual partner preference, hypothalamic morphology and aromatase in rams. Physiol. Behav. $83,233-245$.

Roselli, C.E., Reddy, R.C., Kaufman, K.R., 2011. The development of male-oriented behavior in rams. Front. Neuroendocrinol. 32, 164-169.

Russell, N.V., Ogaga-Mgbonyebi, E.V., Habteab, B., Dunigan, A.I., Tesfay, M.A., Clancy, A.N., 2012. Sexual responses of the male rat medial preoptic area and media amygdala to estrogen II: site specific effects of selective estrogenic drugs. Horm. Behav. 62, 58-66.

Savic, I., Berglund, H., Gulyas, B., Roland, P., 2001. Smelling of odorous sex hormonelike compounds causes sex-differentiated hypothalamic activations in humans. Neuron 31, 661-668.

Savic, I., Berglund, H., Lindstrom, P., 2005. Brain response to putative pheromones in homosexual men. Proc. Natl. Acad. Sci. USA 102, 7356-7361.

Saxton, T.K., Lyndon, A., Little, A.C., Roberts, S.C., 2008. Evidence that androstadienone, a putative human chemosignal, modulates women's attributions of men's attractiveness. Horm. Behav. 54, 597-601.

Schaefer, M.L., Yamazaki, K., Osada, K., Restrepo, D., Beauchamp, G.K., 2002. Olfactory fingerprints for major histocompatibility complex-determined body odors II: relationship among odor maps, genetics, odor composition, and behavior. J. Neurosci. 22, 9513-9521.

Schaefer, M.L., Young, D.A., Restrepo, D., 2001. Olfactory fingerprints for major histocompatibility complex-determined body odors. J. Neurosci. 21, 24812487.

Shang, Y., Dluzen, D.E., 1998. Castration reduces olfactory bulb norepinephrine transporter function as indicated by responses to noradrenergic uptake blockers. Brain Res. 779, 119-124.

Shang, Y., Dluzen, D.E., 2001. Nisoxetine infusion into the olfactory bulb enhances the capacity for male rats to identify conspecifics. Neuroscience 104, 957-964.

Shughrue, P.J., Lane, M.V., Merchenthaler, I., 1997. Comparative distribution of estrogen receptor-alpha and -beta mRNA in the rat central nervous system. J. Comp. Neurol. 388, 507-525.

Signoret, J.P., 1967. Attraction de la femelle en oestrus par le male chez les porcins. Rev. Comp. Anim. 4, 10-22.

Signoret, J.P., 1970. Reproductive behaviour of pigs. J. Reprod. Fertil. Suppl. 11, Suppl $11: 105+$

Sorwell, K.G., Wesson, D.W., Baum, M.J., 2008. Sexually dimorphic enhancement by estradiol of male urinary odor detection thresholds in mice. Behav. Neurosci. 122, 788-793.

Sosulski, D.L., Bloom, M.L., Cutforth, T., Axel, R., Datta, S.R., 2011. Distinct representations of olfactory information in different cortical centres. Nature $472,213-216$

Swann, J., Rahaman, F., Bijak, T., Fiber, J., 2001. The main olfactory system mediates pheromone-induced fos expression in the extended amygdala and preoptic area of the male Syrian hamster. Neuroscience 105, 695-706.

Tachikawa, K.S. Yoshihara, Y. Kuroda, K.O., 2013. Behavioral transition from attack to parenting in male mice: a crucial role of the vomeronasal system. J. Neurosci. $33,5120-5126$.

Thompson, J.A., Salcedo, E., Restrepo, D., Finger, T.E., 2012. Second order input to the medial amygdala from olfactory sensory neurons expressing the transduction channel TRPM5. J. Comp. Neurol. 520, 1819-1830.

Tirindelli, R., Dibattista, M., Pifferi, S., Menini, A., 2009. From pheromones to behavior. Physiol. Rev. 89, 921-956. 
Trotier, D., Eloit, C., Wassef, M., Talmain, G., Bensimon, J., Doving, K., Ferrand, J., 2000. The vomeronasal cavity in adult humans. Chem. Senses 25, 369-380.

Turaga, D., Holy, T.E., 2012. Organization of vomeronasal sensory coding revealed by fast volumetric calcium imaging. J. Neurosci. 32, 1612-1621.

Turner, B.H., Gupta, K.C., Mishkin, M., 1978. The locus and cytoarchitecture of the projection areas of the olfactory bulb in Macaca mulatta. J. Comp. Neurol. 177, 381-396.

Tye, K.M., Deisseroth, K., 2012. Optogenetic investigation of neural circuits underlying brain disease in animal models. Nat. Rev. Neurosci. 13, 251-266.

Veyrac, A., Bakker, J., 2011. Postnatal and adult exposure to estradiol differentially influences adult neurogenesis in the main and accessory olfactory bulb of female mice. FASEB J. 25, 1048-1057.

Wersinger, S.R., Baum, M.J., 1997. Sexually dimorphic processing of somatosensory and chemosensory inputs to forebrain luteinizing hormone-releasing hormone neurons in mated ferrets. Endocrinology 138, 1121-1129.

Wesson, D.W., Keller, M., Douhard, Q., Baum, M.J., Bakker, J., 2006. Enhanced urinary odor discrimination in female aromatase knockout (ArKO) mice. Horm. Behav. 49, 580-586.

Woodley, S.K., Baum, M.J., 2004. Differential activation of glomeruli in the ferret's main olfactory bulb by anal scent gland odours from males and females: an early step in mate identification. Eur. J. Neurosci. 20, 1025-1032.

Woodley, S.K., Cloe, A.L., Waters, P., Baum, M.J., 2004. Effects of vomeronasal organ removal on olfactory sex discrimination and odor preferences of female ferrets. Chem. Senses 29, 659-669.
Wyart, C., Webster, W.W., Chen, J.H., Wilson, S.R., McClary, A., Khan, R.M., Sobel, N., 2007. Smelling a single component of male sweat alters levels of cortisol in women. J. Neurosci. 27, 1261-1265.

Wyatt, T.D., 2010. Pheromones and signature mixtures: defining species-wide signals and variable cues for identity in both invertebrates and vertebrates. J. Comp. Physiol. A Neuroethol. Sens Neural Behav. Physiol. 196, 685-700.

$\mathrm{Xu}, \mathrm{F}$., Greer, C.A., Shepherd, G.M., 2000. Odor maps in the olfactory bulb. J. Comp. Neurol. 422, 489-495.

Zacharias, R., de Catanzaro, D., Muir, C., 2000. Novel male mice disrupt pregnancy despite removal of vesicular-coagulating and preputial glands. Physiol. Behav. $68,285-290$.

Zhang, J.X., Soini, H.A., Bruce, K.E., Wiesler, D., Woodley, S.K., Baum, M.J., Novotny, M.V., 2005. Putative chemosignals of the ferret (Mustela furo) associated with individual and gender recognition. Chem. Senses 30, 727-737. 